Research Article

\title{
Experimental Research of Continuous Concrete Beams with GFRP Reinforcement
}

\author{
Nikola Baša (D), Mladen Ulićević, and Radomir Zejak \\ University of Montenegro, Faculty of Civil Engineering, Cetinjski put bb, 81000 Podgorica, Montenegro \\ Correspondence should be addressed to Nikola Baša; nik.ma@t-com.me
}

Received 8 June 2018; Accepted 13 September 2018; Published 18 October 2018

Academic Editor: Dongsheng Li

Copyright (c) 2018 Nikola Baša et al. This is an open access article distributed under the Creative Commons Attribution License, which permits unrestricted use, distribution, and reproduction in any medium, provided the original work is properly cited.

\begin{abstract}
Continuous beams are often used within RC structures, which are exposed to aggressive environmental impact. The use of the fiber-reinforced polymer (FRP) reinforcement in these objects and environments has a big significance, taking into account tendency of steel reinforcement to corrode. The main aim of these research studies is to estimate ability of continuous beams with glass FRP (GFRP) reinforcement to redistribute internal forces, as a certain way of ductility and desirable behaviour of RC structures. This paper gives the results of experimental research of seven continuous beams, over two spans of $1850 \mathrm{~mm}$ length, cross-section of $150 \times 250 \mathrm{~mm}$, that are imposed to concentrated forces in the middle of spans until failure. Six beams were reinforced with different longitudinal GFRP and same transverse GFRP reinforcements, and one steel-reinforced beam was adopted as a control beam. The main varied parameters represent the type of GFRP reinforcement and ratio of longitudinal reinforcement at the midspan and at the middle support, i.e., design moment redistribution. The results of the research have shown that moment redistribution in continuous beams of GFRP reinforcement is possible, without decreasing the load-carrying capacity, compared to elastic analysis. The test results have also been compared to current code provisions, and they have shown that the American Concrete Institute (ACI) $440.1 \mathrm{R}-15$ well predicted the failure load for continuous beams with GFRP reinforcement. On the contrary, current design codes underestimate deflection of continuous beams with GFRP reinforcement, especially for higher load levels. Consequently, a modified model for calculation of deflection is proposed.
\end{abstract}

\section{Introduction}

For RC structures, elements reinforced with steel reinforcement are still used nowadays. As preventing of steel reinforcement to corrode in RC structures could be expensive and very often without significant effects, FRP internal reinforcement is lately used as a replacement of steel reinforcement in RC structures, especially in aggressive environments. Nowadays, there is a significant number of structures such as garages, bridges, retaining walls, reservoirs, and marine objects, within which FRP reinforcement is successfully applied at RC structural elements. Continuous concrete beams are commonly used in some of these structures, especially in bridges, overpasses, marine structures, and parking garages. Additionally, continuous beams with FRP reinforcement can also find their application in facilities with magnetic scanning equipment, laboratories, airport towers, and MRI rooms in hospitals and other facilities with equipment requiring electrical and magnetic neutrality, where the presence of steel reinforcement can have an adverse effect on the usability of devices in these facilities.

Due to different mechanical and deformation characteristics of FRP reinforcement, as high tensile strength and low modulus of elasticity, the behavior of RC elements is considerably different compared to RC elements with steel reinforcement. Concerning the fact that FRP reinforcement demonstrates linear elastic behavior up to failure, meaning demonstrating lack of material nonlinearity, there is a question of ability of this material, in conjunction with concrete, to realize load redistribution in statically indeterminate structures [1]. Regarding the significant 
contribution of the elastic redistribution in continuous RC beams with steel reinforcement [2], it is expected that continuous beams with FRP reinforcement give certain ability to redistribute the internal force. Redistribution of internal forces is expected as the result of cracks development and adopted reinforcement within them [1, 3]. In other words, one of the basic characteristics of ductility is considered, i.e., variation of stiffness without loss of capacity of the section [4].

\section{Background}

So far, thorough theoretical and experimental research studies have been carried out on simple supported beams with FRP reinforcement in order to evaluate behavior regarding failure modes, load-carrying capacity, deflection, and cracks [5-13]. Therefore, provisions of certain codes are based on conclusions given on simple supported beams. A great number of formulas and equations are suggested to determine response of elements with FRP reinforcement at service load conditions, especially when deflection is concerned (Toutanji and Saafi [7], Yost et al. [8], Bischoff and Gross [9], Mousavi and Esfahani [10], and Ju et al. [11]).

Certain experimental and theoretical research studies were also carried out on continuous beams with FRP reinforcement $[1,3,4,14-22]$, but not as much as they were carried out on simple beams. Mostofinejad [4] carried out research studies on two continuous beams with steel reinforcement and eight underreinforced and overreinforced continuous beams with CFRP reinforcement. These research studies showed that moment redistribution in continuous beams with FRP reinforcement is possible, although in lower degree than in steel-reinforced beams. Overreinforced beams with FRP reinforcement fulfill requirements of serviceability, while underreinforced beams, designed to experience failure by FRP bars, usually do not fulfill these conditions. Moreover, overreinforced continuous beams show significant deformations before failure, which was determined as a distinctive way of ductility. Grace et al. [14] researched behavior and ductility of continuous beams, $\mathrm{T}$ cross-section, reinforced by different types of longitudinal and transverse FRP reinforcements (GFRP and CFRP). It was indicated on different failure modes and beam ductility with FRP reinforcement, in relation to beams with steel reinforcement. It was also concluded that the use of GFRP stirrups increases shear deformations. As a result of that, total deformations increase in the midspan of continuous beams. El-Mogy et al. [1] conducted the research on four continuous beams of rectangular cross-section with GFRP, CFRP, and steel reinforcement by varying the ratio of longitudinal reinforcement in the midspan and the middle support. It was concluded that continuous beams with FRP reinforcement are capable of redistributing the moments from middle support towards the midspan of $23 \%$ in relation to elastic analysis, similar to the fact that they do not cause adversely effects concerning the beam characteristics, neither at service loads, nor at failure loads. Moreover, it was concluded that the increase of reinforcement in the midspan of continuous beams in relation to section at the middle support has positive effects on the increase of load capacity of beams, decrease of deflections, and postponing of propagation of cracks in the beams' midspan. Habeeb and Ashour [15] noticed signs of moment redistribution within overreinforced beams in the bottom zone in the midspan, during the experimental research studies on three continuous beams with different combinations of GFRP longitudinal reinforcement in the midspan and at the middle support. As a key factor of increasing the load capacity and limitation of deflection and propagation of cracks, the increase of the reinforcement in the bottom zone of the midspan was noticed. In the scope of same experimental research studies, Ashour and Habeeb [16] conducted the research on three continuous beams with CFRP reinforcement, designed with different configurations of reinforcement along the beam, so as to experience the failure by CFRP bars. Intolerant wide cracks at the middle support were noticed in all beams as a result of debonding of CFRP bars from concrete. It was concluded that the basic parameter of increasing the load capacity of continuous beams was the amount of CFRP reinforcement in the bottom zone in the midspan. Other recent research studies on continuous beams $[3,17,18,20]$ also pointed out to the importance of increasing the reinforcement in the bottom zone of the beam midspan, as a result of redistribution of moment over the middle support.

The approach that in continuous beams reinforced with FRP reinforcement, moment redistribution in critical sections is not allowed could be conservative [21]. Therefore, it needs additional research studies. For this purpose, it is necessary to define more clearly and precisely the influence of ratio of longitudinal reinforcement at the midspan and at the middle support on behavior of continuous beams with FRP reinforcement. The main aim of these research studies is consideration of behavior of continuous beams reinforced with GFRP reinforcement during loading until failure, with different configurations of reinforcement along the beam. Thus, in these experimental research studies for the same design failure load, for every type of GFRP reinforcement, three models with different configurations of reinforcement along the beam were used. Experimental results are discussed and evaluated based on failure modes, cracking, deflection, moment redistribution, and strains in concrete and reinforcement and compared to code predictions regarding the load-carrying capacity and deflection. Based on experimental results, a modified model for better prediction of deflection of continuous beams with GFRP reinforcement is proposed.

After a literature review, it is concluded that, in very few number of experimental research studies on continuous beams with longitudinal FRP reinforcement, FRP reinforcement for stirrups was used $[3,14,22]$. In the research studies carried out on the beams with FRP reinforcement, steel reinforcement for stirrups was mainly used. In that case, a problem with corrosion of reinforced concrete elements is still present, especially in aggressive environments. The problem increases when it is known that the effects of FRP stirrups and steel stirrups on behavior of 
the beams are different [14]. Regarding the previously mentioned, in these experimental research studies, besides the longitudinal GFRP reinforcement, it was also used for stirrups.

\section{Experimental Program}

The experimental program consisted of six continuous beams of total length of $3940 \mathrm{~mm}$, at two equal spans of $1850 \mathrm{~mm}$ length, with a rectangular cross-section of $150 \times 250 \mathrm{~mm}$ and with longitudinal and transverse GFRP reinforcement. In addition, a single beam with steel reinforcement was adopted as a control beam. All beams were examined up to failure, loaded by concentrated forces in the middle of both spans. The beams were divided into two series, with different GFRP longitudinal bars, and all were designed for a similar failure load. Dimensions and geometry of continuous beams and load disposition are given in Figure 1.

Considering beams of Series 1, longitudinal reinforcement of beam G1-0 was designed for the elastic bending moments along the beam, while reinforcement of beams G1-15 and G1-25 was obtained for assumed moment redistribution at the middle support of $15 \%$ and $25 \%$, respectively. For the beams G1-15 and G1-25, this meant smaller amount of reinforcement at the middle support and higher amount of reinforcement at the midspan compared to beam G1-0. In this way, for designed failure load, models with $0 \%$ (G1-0), 15\% (G1-15), and 25\% (G1-25) of designed moment redistribution from the middle support to the midspan were obtained. The reinforcement ratio of the beam G1-0 at the middle support has been chosen so as to be approximately 3 times higher than the balanced reinforcement ratio, which corresponds to recommendations of codes that beams with FRP reinforcement should be designed to experience concrete compression failure. In this way, it was provided, after the moment redistribution was made, that all cross-sections, in all beams of Series 1, were designed to have reinforcement ratio above the balanced reinforcement ratio. The control beam with steel reinforcement (S1-15) was designed to achieve the moment redistribution of $15 \%$ from the middle support to the midspan. The beams of Series 2 were designed in the same way as the beams of Series 1, only with different types of longitudinal GFRP reinforcement. Models with $0 \%$ (G2-0), $15 \%$ (G2-15), and 25\% (G2-25) of designed moment redistribution from the middle support to the beam midspan were also adopted.

All beams were designed in accordance with ACI 440.1R15 [23], while CSA S806-12 [24], CNR-DT-203 [25], and EC2-04 [26] were used as control. For shear reinforcement, GFRP stirrups were adopted for beams with GFRP longitudinal reinforcement, similar to steel stirrups for the beam S1-15 with longitudinal steel reinforcement. Stirrups with a diameter of $8 \mathrm{~mm}$ were adopted at the space of $60 \mathrm{~mm}$ for interior shear span and at the space of $120 \mathrm{~mm}$ for exterior shear span for all beams, in order to prevent beams to experience failure due to shear. Details of reinforcing for experimental models are given in Table 1.

\subsection{Materials}

3.1.1. Reinforcement. In these experimental research studies, two types of GFRP reinforcement were used: wrapped GFRP bars with $70 \%$ of longitudinal glass fibers (E-glass) in total volume, impregnated in the unsaturated polyester matrix for Series 1 (marked G1), and GFRP reinforcement with $75 \%$ of longitudinal glass fibers (E-glass), impregnated in an epoxy matrix for Series 2 (marked G2). GFRP reinforcement with polyester was wrapped in glass fibers, while GFRP reinforcement with epoxy resin was with rebars (Figure 2). In all beams, GFRP stirrups with polyester were used. According to the prospect of the manufacturer, GFRP reinforcement with the polyester matrix has a nominal tensile strength of $f=700 \mathrm{MPa}$ and a modulus of elasticity of $E=40000 \mathrm{MPa}$, while GFRP reinforcement with the epoxy matrix has a nominal tensile strength of $f=1100 \mathrm{MPa}$ and a modulus of elasticity of $E=50000 \mathrm{MPa}$. In order to define design moment redistribution more precisely and to provide identical failure load for beams of the same series, different diameters of GFRP and steel reinforcements were used along the beam. For each diameter of GFRP reinforcement, real cross-sectional areas of the bar, similar to the equivalent diameter, on at least five samples of $200 \mathrm{~mm}$ length were determined. Also, for each diameter of the bars, five samples were examined to tension until failure in order to define mechanical and deformation characteristics of GFRP reinforcement, all in accordance with ACI 440.3R-12 [27]. Average values of the test results are given in Table 2.

3.1.2. Concrete. Two designed classes of concrete of $40 \mathrm{MPa}$ and $45 \mathrm{MPa}$ were used in experimental research studies, for the beams of Series 1 and Series 2, respectively, in order to provide a similar failure load for all beams. For each series of beams, concrete compressive strength after 28 days was obtained according to the investigation of 8 cubes of $150 \mathrm{~mm}$ edge, 8 cubes of $200 \mathrm{~mm}$ edge, and 17 cylinders of $150 / 300 \mathrm{~mm}$ dimension. Average values of test results of concrete compressive strength on cylinders $150 / 300 \mathrm{~mm}$ are given in Table 1.

3.2. Test Setup and Instrumentation. Continuous beams consisted of two equal spans placed on three supports over steel bearings. End supports were designed as horizontally movable, while the middle support was designed to prevent horizontal movement. Experimental models were examined in a closed frame which consisted of a unique system of horizontal beams and vertical ties. The load was placed over two hydraulic presses, capacity of $200 \mathrm{kN}$, in the middle of both spans.

Twelve electrical strain gauges were placed on longitudinal tension reinforcement in both bottom and upper zones of each beam. Also, three strain gauges were placed on compression reinforcement according to the scheme shown in Figure 3. Two strain gauges were placed on the compression zone of continuous beams in critical sections at $1 \mathrm{~cm}$ from the bottom one (at the middle support), similar to that at the upper edge of concrete (in the midspan), so as 

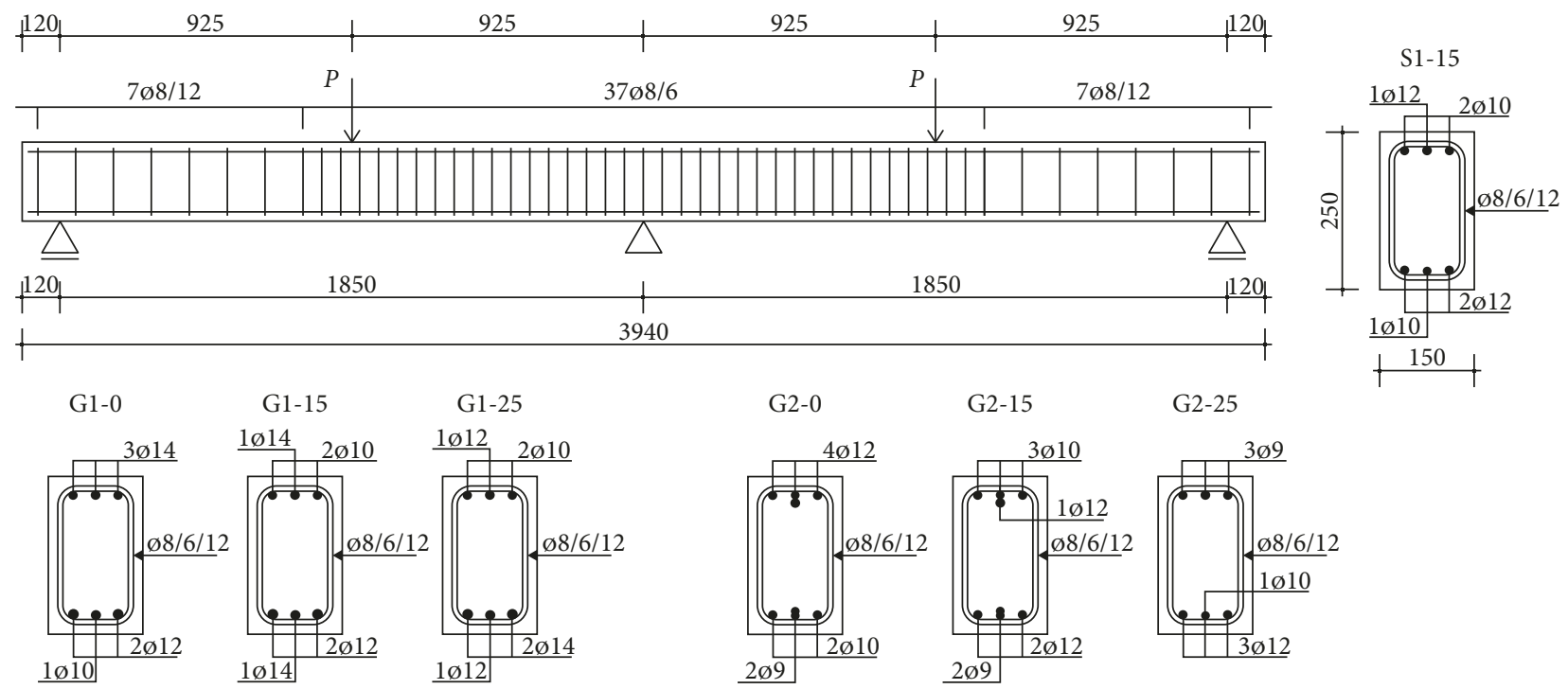

FIgURE 1: Geometry and reinforcement details for tested beams (all dimensions are in $\mathrm{mm}$ ).

TABLE 1: Reinforcement details and compressive strength of concrete for tested beams.

\begin{tabular}{|c|c|c|c|c|c|c|c|c|c|c|c|c|}
\hline \multirow{3}{*}{ Beam } & \multirow{3}{*}{$\begin{array}{l}\text { Day of } \\
\text { testing }\end{array}$} & \multicolumn{5}{|c|}{ Middle support-top reinforcement } & \multicolumn{5}{|c|}{ Midspan-bottom reinforcement } & \multirow{3}{*}{$\begin{array}{c}\text { Concrete } \\
\text { compressive } \\
\text { strength } f_{\mathrm{c}}(\mathrm{MPa})\end{array}$} \\
\hline & & \multirow{2}{*}{$\begin{array}{l}\text { Longitudinal } \\
\text { reinforcement }\end{array}$} & \multirow{2}{*}{$\begin{array}{c}\mathrm{EA} \\
(\mathrm{kN})\end{array}$} & \multicolumn{3}{|c|}{$\begin{array}{l}\text { Reinforcement } \\
\text { ratio }(\mathrm{ACI})\end{array}$} & \multirow{2}{*}{$\begin{array}{l}\text { Longitudinal } \\
\text { reinforcement }\end{array}$} & \multirow{2}{*}{$\begin{array}{c}\mathrm{EA} \\
(\mathrm{kN})\end{array}$} & \multicolumn{3}{|c|}{$\begin{array}{l}\text { Reinforcement } \\
\text { ratio }(\mathrm{ACI})\end{array}$} & \\
\hline & & & & $\begin{array}{c}\rho_{\mathrm{f}} \\
(\%)\end{array}$ & $\begin{array}{l}\rho_{\mathrm{fb}} \\
(\%)\end{array}$ & $\rho_{\mathrm{f}} / \rho_{\mathrm{fb}}$ & & & $\begin{array}{c}\rho_{\mathrm{f}} \\
(\%)\end{array}$ & $\begin{array}{l}\rho_{\mathrm{fb}} \\
(\%)\end{array}$ & $\rho_{\mathrm{f}} / \rho_{\mathrm{fb}}$ & \\
\hline S1-15 & 28 & $2 \varnothing 10+1 \varnothing 12$ & 49526 & 0.82 & 1.26 & 0.65 & $2 \emptyset 12+1 \emptyset 10$ & 54763 & 0.92 & 1.31 & 0.71 & 42.2 \\
\hline G1-0 & 29 & $3 \varnothing 14$ & 20318 & 1.40 & 0.46 & 3.01 & $2 \varnothing 12+1 \varnothing 10$ & 13558 & 1.00 & 0.57 & 1.75 & 42.2 \\
\hline $\begin{array}{l}\text { G1- } \\
15\end{array}$ & 30 & $2 \varnothing 10+1 \varnothing 14$ & 12604 & 0.86 & 0.53 & 1.63 & $2 \varnothing 12+1 \varnothing 14$ & 17415 & 1.19 & 0.46 & 2.58 & 42.2 \\
\hline $\begin{array}{l}\text { G1- } \\
25\end{array}$ & 30 & $2 \varnothing 10+1 \varnothing 12$ & 11153 & 0.74 & 0.51 & 1.44 & $2 \varnothing 14+1 \varnothing 12$ & 18867 & 1.25 & 0.45 & 2.80 & 42.2 \\
\hline G2-0 & 28 & $4 \varnothing 12$ & 17654 & 1.11 & 0.33 & 3.35 & $2 \varnothing 10+2 \varnothing 9$ & 10734 & 0.65 & 0.29 & 2.27 & 50.2 \\
\hline $\begin{array}{l}\text { G2- } \\
15\end{array}$ & 29 & $3 \varnothing 10+1 \varnothing 12$ & 12482 & 0.79 & 0.33 & 2.37 & $2 \varnothing 12+2 \varnothing 9$ & 14182 & 0.86 & 0.32 & 2.69 & 50.2 \\
\hline $\begin{array}{l}\text { G2- } \\
25\end{array}$ & 30 & $3 \varnothing 9$ & 8033 & 0.48 & 0.29 & 1.70 & $3 \varnothing 12+1 \varnothing 10$ & 15930 & 1.10 & 0.37 & 3.02 & 50.2 \\
\hline
\end{tabular}

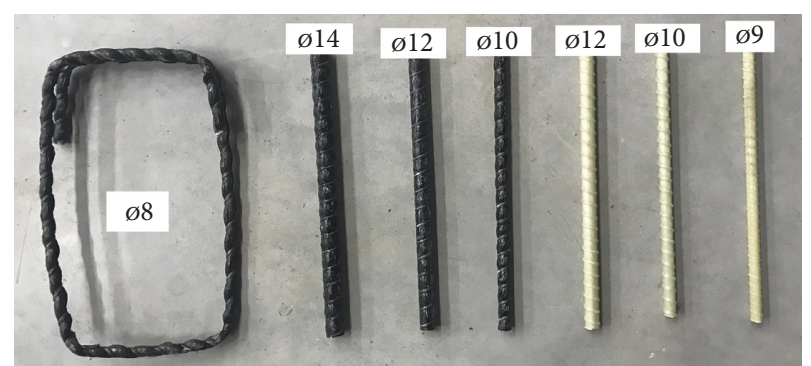

FIgURE 2: Samples of GFRP longitudinal and transverse reinforcement.

strains could be measured in compression concrete. Deflections of continuous beams along the span were registered by LVDT transducers $1 / 100 \mathrm{~mm}$ and $1 / 50 \mathrm{~mm}$ of accuracy, which were placed at the level of the bottom edge of the beam. Three LVDT transducers were attached on every span, in the middle, in the quarter, and three quarters of the beam span. For each increment, i.e., load level, appearance and development of vertical and possibly shear cracks along the beam were registered. Maximal width of a few cracks was measured in critical sections, in the span and at the middle support by a microscopic magnifier (Zeiss) with $0.025 \mathrm{~mm}$ of accuracy. Load cells were placed below the end supports, capacity of $100 \mathrm{kN}$, due to measurement of end reactions. The scheme of the measuring equipment of continuous beams is given in Figures 3 and 4 .

3.3. Test Procedure. The load was applied to the beams as monotonically static growing load in increments from zero up to the failure. At the beginning of the tests, load was applied in increments of approximately $2-3 \mathrm{kN}$ and after development of first cracks in increments of $5 \mathrm{kN}$. When approximately $80 \%$ of the estimated failure load was reached, again the load was applied in increments of $2-3 \mathrm{kN}$. 
TABLE 2: Mechanical and deformation characteristics of GFRP reinforcement.

\begin{tabular}{|c|c|c|c|c|c|}
\hline Diameter & $\begin{array}{l}\text { Real area of bar } \\
\quad \mathrm{A}\left(\mathrm{mm}^{2}\right)\end{array}$ & Tensile strength $f_{\mathrm{u}}(\mathrm{MPa})$ & Yield strength $f_{\mathrm{y}}(\mathrm{MPa})$ & Modulus of elasticity $E(\mathrm{MPa})$ & Ultimate strain $\varepsilon_{\mathrm{u}}(\% \mathrm{o})$ \\
\hline GFRP-1-Ø8 & 39.9 & 714.8 & - & 42640 & 16.8 \\
\hline $\begin{array}{l}\text { GFRP-1- } \\
\varnothing 10\end{array}$ & 70.6 & 703.1 & - & 41300 & 17.0 \\
\hline $\begin{array}{l}\text { GFRP-1- } \\
\varnothing 12\end{array}$ & 116.1 & 865.9 & - & 45832 & 18.9 \\
\hline $\begin{array}{l}\text { GFRP-1- } \\
\varnothing 14\end{array}$ & 152.8 & 813.5 & - & 44324 & 18.4 \\
\hline GFRP-2-Ø9 & 53.3 & 1170.4 & - & 50235 & 23.3 \\
\hline $\begin{array}{l}\text { GFRP-2- } \\
\varnothing 10\end{array}$ & 61.5 & 1059.3 & - & 43734 & 24.2 \\
\hline $\begin{array}{l}\text { GFRP-2- } \\
\varnothing 12\end{array}$ & 91.6 & 1060.4 & - & 48182 & 22.0 \\
\hline Steel-Ø10 & 78.5 & 639.5 & 509.6 & 188064 & $2.7^{\mathrm{a}}$ \\
\hline Steel-Ø12 & 113.1 & 622.5 & 452.7 & 176835 & $2.6^{\mathrm{a}}$ \\
\hline
\end{tabular}

${ }^{a} \varepsilon_{\mathrm{y}}=$ yield strain of steel reinforcement.
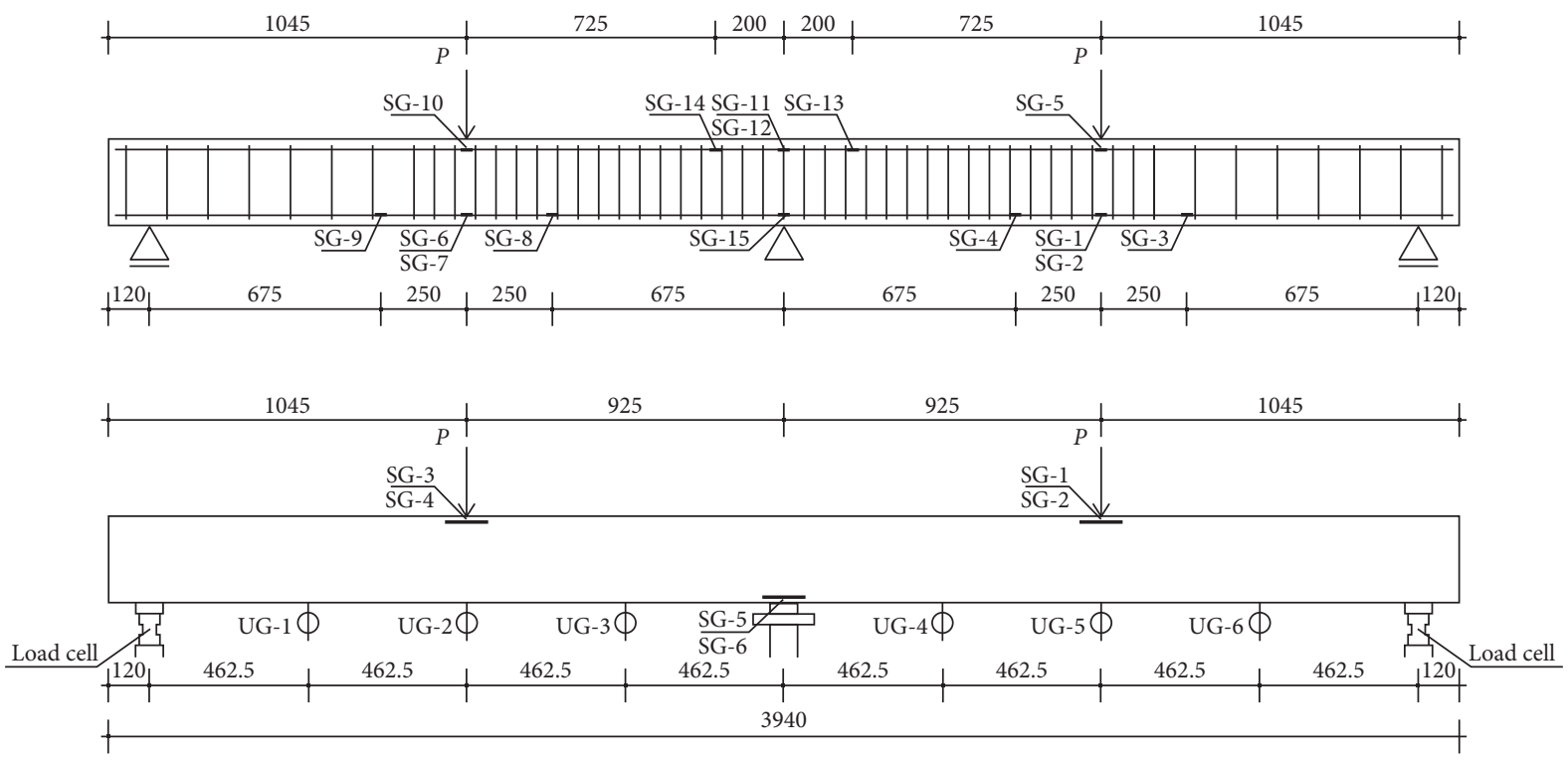

- SG - Strain gauge on reinforcement

- SG - Strain gauge on concrete

$\varnothing$ UG - Transducers for measure the deflection

Figure 3: Experimental setup and instrumentation for tested beams (all dimensions are in $\mathrm{mm}$ ).

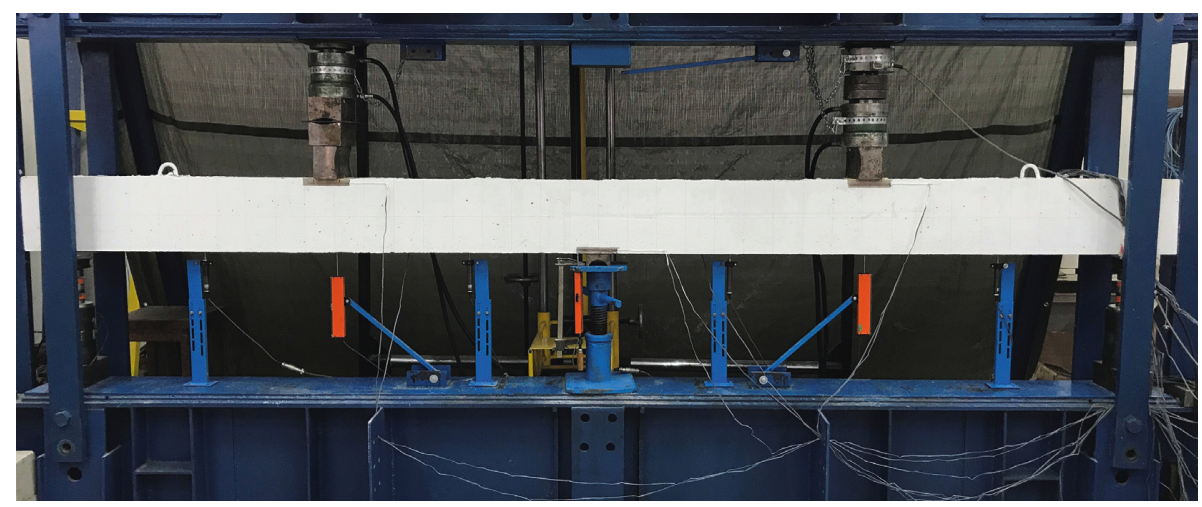

FIGURE 4: Equipped continuous beam before testing. 
Speed of load exposure of each increment was approximately $5 \mathrm{kN} / \mathrm{min}$. All electronic data were collected in the computer using the data logger.

\section{Test Results}

4.1. Modes of Failure. All beams of Series 1 and Series 2 were designed to experience concrete compression failure. Beam S1-15 demonstrated typical ductile flexural behavior, with high values of strains and deflections before failure. At the middle support, existing cracks experienced significant widths at failure. First, the tensile reinforcement yielded at the middle support, and after that, tensile reinforcement in the beam midspan. The failure of the beam G1-0 was initiated by concrete compression failure in the midspan in combination with shear, when one crack in the span diagonally propagated toward the load location. This leads to rupture of GFRP bars in the compressed zone by the dowel effect and one GFRP stirrup at the location of its bending. Within the beam G1-15, concrete compression failure took place at the middle support, when one crack near the support diagonally propagated toward the support. The failure of the beam G1-25 appeared at the same time, at the middle support, where concrete crushing was followed by the shear, and at the midspan, where concrete crushing was manifested by spalling of the cover in the extension of the diagonal crack that occurred in the exterior shear span.

The failure mode of the beams G2-0 and G2-25 was similar, initiated by concrete compression failure in the midspan in combination with shear, when one crack in the interior shear span diagonally propagated toward the load location. The failure at the midspan was followed by concrete crushing in the compression zone at the middle support within both beams. Also, in beam G2-25 at the same time, concrete crushing was manifested by spalling of the cover in the midspan in the extension of the diagonal crack that occurred in the exterior shear span. Within the beam G2-15, concrete compression failure took place at the middle support in combination with shear, with the characteristic bang. All longitudinal compressed and tensioned GFRP bars and stirrups ruptured at that section by the dowel effect. The failure modes of all beams are given in Figure 5. It can be concluded that all continuous beams with GFRP reinforcement experienced concrete compression failure combined with shear, while beam with steel reinforcement experienced ductile flexural tension failure.

4.2. Crack Patterns. In Table 3, failure loads are given, similar to the first crack loads in the midspan and at the middle support for all beams. It is evident that the first crack load was significantly higher in the beam S1-15, than in the beams with GFRP reinforcement, without exception. This could be attributed to high modulus of elasticity of steel reinforcement compared to GFRP reinforcement (3.8-4.5 times higher), which leads to conclusion that the cracking moment does not only depend on the concrete tension strength but also on the modulus of elasticity of reinforcement. Concerning all beams with GFRP reinforcement, the first cracks at the midspan and at the middle support were vertical, and they appeared almost simultaneously, at very similar loads. Moreover, especially for the beams of Series 1, right after the appearance, cracks significantly propagated along the height and entered the last quarter of section height, which additionally affected the decrease of stiffness of this section.

Appearance of new cracks and propagation of existing cracks in the beams of Series 1 with GFRP reinforcement stabilized at load that corresponded to approximately $60 \%$ of the failure load. The space between cracks, in average, was 120 to $180 \mathrm{~mm}$, and it did not match the space between stirrups. It is evident that, in beams with GFRP reinforcement, a smaller number of cracks occurred than in the beam S1-15 with steel reinforcement, where the space between cracks was from 60 to $100 \mathrm{~mm}$ in the interior span, which basically matched the space between stirrups. This indicated poor bond strength between GFRP reinforcement and surrounding concrete, which caused great wideness on already developed cracks in critical sections. This phenomenon was also recorded by a few researchers who examined beams with FRP reinforcement [16]. Concerning the beams G1-15 and G1-25, it was a visible appearance of long horizontal cracks in the tension zone at loads near failure, which implies, due to large deflections, slipping of reinforcement from concrete in that part of the beam (Figure 5).

Concerning beams of Series 2, with GFRP reinforcement with rebars, the number of cracks was greater with less widths, compared to the beams of Series 1 . Cracks appeared in the sagging and in the hogging moment region until failure, regarding the fact that an utmost number of them formed until the load that corresponded to approximately $60 \%$ of failure load. The development of the cracks with increasing load corresponded fully to the adopted reinforcement in critical sections; i.e., the higher amount of reinforcement corresponded to a higher number of formed cracks in the section. The largest number of cracks at the middle support formed in the beam G2-0, with an extremely wide hogging zone where cracks appeared, due to the largest axial stiffness of the reinforcement compared to the beams G2-15 and G2-25. In the midspan, the most number of cracks, with the widest sagging zone, appeared in the beam G2-25, with the largest amount of reinforcement in the midspan. The development of the cracks in the beams of Series 2 was similar to that in the beam S1-15 and corresponded to the space between stirrups, indicating the good bond strength between GFRP reinforcement and surrounding concrete. The more pronounced diagonal cracks at higher load levels for the beams of Series 2, especially in the interior shear span, compared to the beam S1-15, indicated an increase of the shear stresses in the beams with GFRP reinforcement, which can be directly attributed to the use of GFRP stirrups, instead of steel stirrups. This was particularly pronounced in the beam G2-0, in which, due to the higher axial stiffness of reinforcement at the middle support and achieved "opposite" redistribution of internal forces (Section 4.5), higher shear stresses in the interior shear span appeared, compared to the beams G2-15 and G2-25, causing 


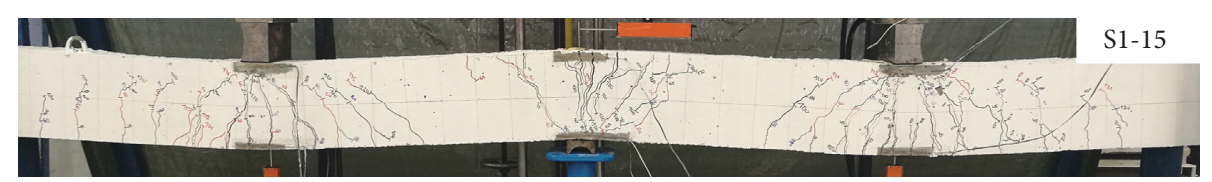

(a)

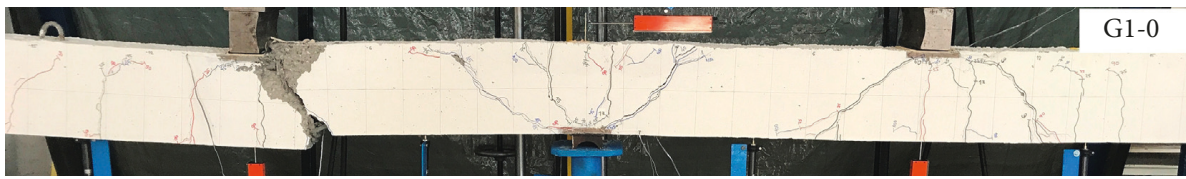

(b)

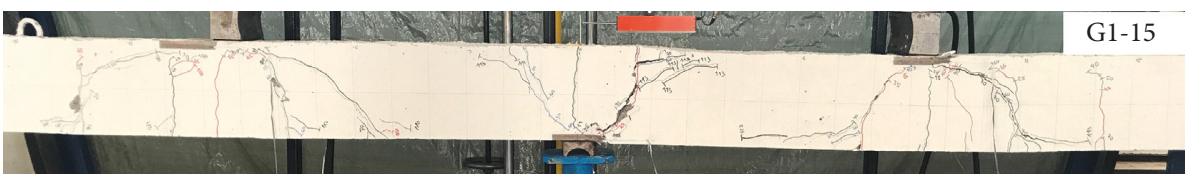

(c)

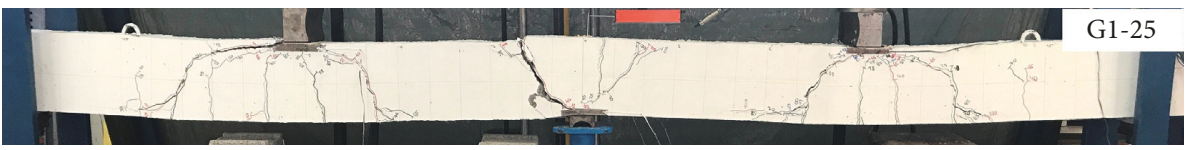

(d)

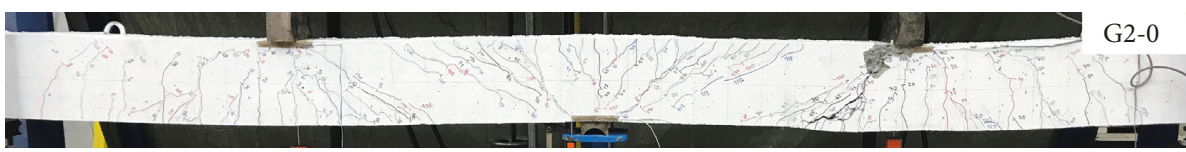

(e)

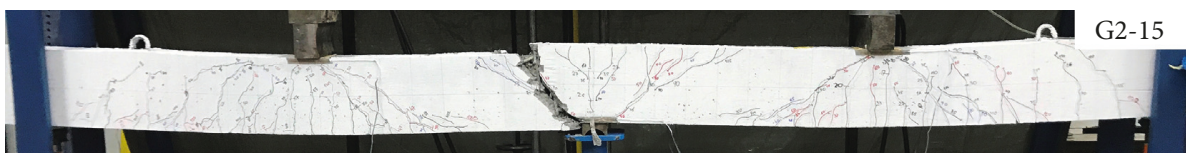

(f)

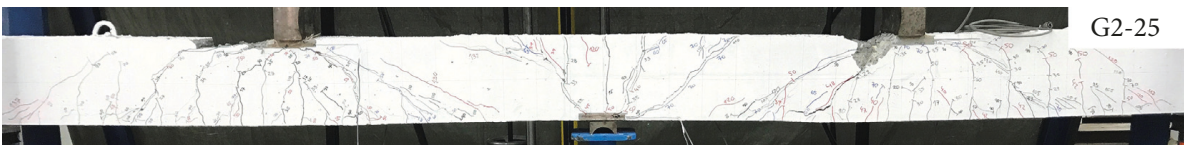

(g)

Figure 5: Failure modes of tested beams. (a) S1-15. (b) G1-0. (c) G1-15. (d) G1-25. (e) G2-0. (f) G2-15. (g) G2-25.

TABLE 3: First crack loads and failure loads.

\begin{tabular}{|c|c|c|c|c|c|c|}
\hline \multirow{2}{*}{ Beam } & \multicolumn{3}{|c|}{ Load at first crack $P_{\mathrm{cr}}(\mathrm{kN})$} & \multirow{2}{*}{ Failure load $P_{\mathrm{u}}(\mathrm{kN})$} & \multicolumn{2}{|c|}{$P_{\mathrm{cr}} / P_{\mathrm{u}}$} \\
\hline & Left midspan & Right midspan & Middle support & & Midspan & Middle support \\
\hline S1-15 & 32 & 32 & 25 & 134.3 & 0.238 & 0.186 \\
\hline G1-0 & 15 & 13 & 13 & 115.6 & 0.112 & 0.112 \\
\hline G1-15 & 11 & 13 & 13 & 115.2 & 0.095 & 0.113 \\
\hline G1-25 & 13 & 13 & 13 & 119.6 & 0.109 & 0.109 \\
\hline G2-0 & 20 & 20 & 17 & 125.2 & 0.160 & 0.136 \\
\hline G2-15 & 17 & 17 & 17 & 124.9 & 0.136 & 0.136 \\
\hline G2-25 & 17 & 17 & 15 & 137.8 & 0.123 & 0.109 \\
\hline
\end{tabular}

a large number of shear cracks at the hogging moment region (Figure 5).

4.3. Crack Width. In Figures 6 and 7, developments of maximal flexural crack widths depending on loads are given for all beams, in the midspan and at the middle support, respectively. It can be seen that beams of Series 1 had larger maximum flexural crack widths than the beams of Series 2 . This is not only the consequence of a bit lower modulus of elasticity of the GFRP reinforcement used in beams of Series 1 but also the consequence of poor bond strength of this 


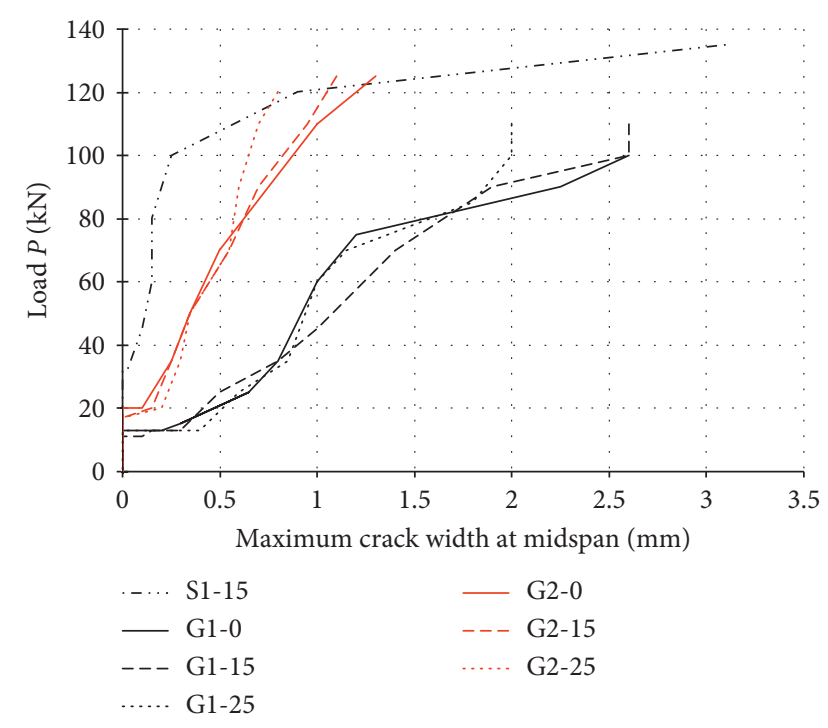

FIgURE 6: Load-maximum crack width relationship at the midspan for tested beams.

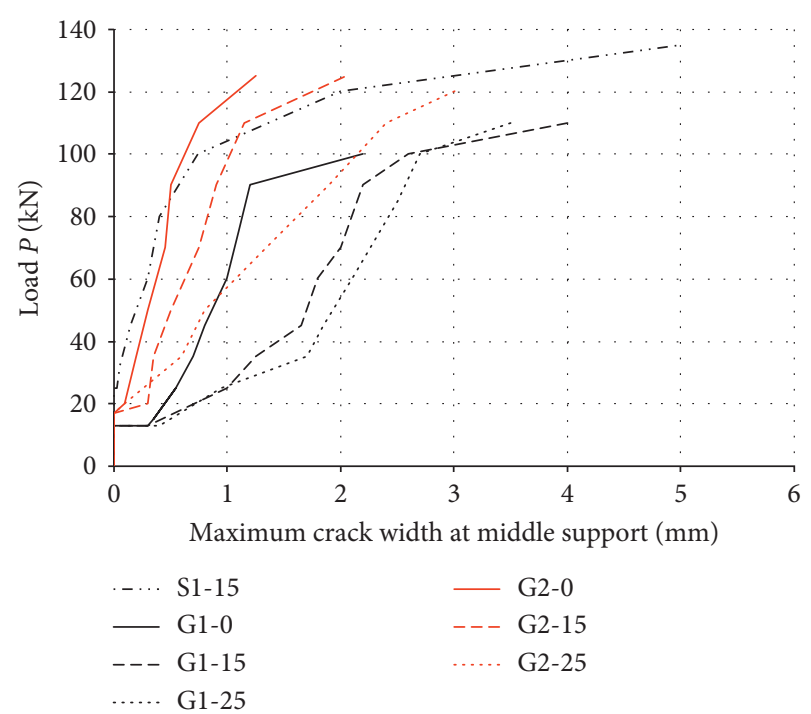

Figure 7: Load-maximum crack width relationship at the middle support for tested beams.

GFRP reinforcement with concrete. Also, beam S1-15 had the smallest crack width in relation to the beams with GFRP reinforcement because of the significantly larger modulus of elasticity of the steel reinforcement compared to the GFRP reinforcement. However, at higher load levels, when the steel reinforcement yielded, the maximum crack widths were greater in the beam S1-15 than in the beams with GFRP reinforcement.

Within the midspan of the beams of Series 1 with GFRP reinforcement, the development of the maximum crack width was much equalized, until loads that corresponded to $40 \%$ of the failure load, regardless of the fact that reinforcement in the beam G1-0 had less stiffness $(\mathrm{EA}=13558 \mathrm{kN})$ in relation to reinforcement of the beams $\mathrm{G} 1-15(\mathrm{EA}=17415 \mathrm{kN})$ and $\mathrm{G} 1-25(\mathrm{EA}=18867 \mathrm{kN})$. At the failure, the smallest maximum crack width in the midspan was in the beam G1-25 with the highest amount of reinforcement in the midspan. At the support, the influence of stiffness of reinforcement was evident, meaning that less axial stiffness of reinforcement at the middle support generated larger crack widths in the beams. Therefore, for the most of different load levels, the largest crack width was in the beam $\mathrm{G} 1-25(\mathrm{EA}=11153 \mathrm{kN})$ and the smallest was in the beam G1-0 $(\mathrm{EA}=20318 \mathrm{kN})$.

Within the beams of Series 2, the axial stiffness of the GFRP reinforcement was clearly expressed on the maximum cracks width, both in the midspan and at the middle support. For initial load levels, the maximum crack width in the midspan was almost uniform for all beams of Series 2. For higher load levels, the beam G2-25 exhibited the smallest maximum crack width with the largest reinforcement axial stiffness in the midspan $(\mathrm{EA}=15930 \mathrm{kN})$, and the beam G2-0 exhibited the largest maximum crack width, with the smallest reinforcement axial stiffness in the midspan $(\mathrm{EA}=10734 \mathrm{kN})$. At the middle support, beam G2-25 exhibited the largest maximum crack width with the smallest reinforcement axial stiffness at the support $(\mathrm{EA}=8033 \mathrm{kN})$, compared to the beams $\mathrm{G} 2-0 \quad(\mathrm{EA}=$ $12482 \mathrm{kN})$ and $\mathrm{G} 2-15(\mathrm{EA}=17654 \mathrm{kN})$.

4.4. Deflection Response. In Figure 8, the diagrams of loadaverage deflection for both spans are given for all beams. It is distinctive for all beams that they showed linear behavior of load-deflection before cracking. Right after the first crack appeared in the beams with GFRP reinforcement, a significant decrease of section stiffness occurred, which is the result of low modulus of elasticity of GFRP reinforcement, and it was manifested by a sudden change in the rate of loaddeflection curves. The beams of Series 1 recorded a higher increase of deflection right before the appearance of cracks, compared to the beams of Series 2 .

Within the beams of Series 1, for the same load level, as expected, deflections in beams with GFRP reinforcement were much higher than in the beam S1-15 with steel reinforcement. This is a result of larger crack widths in the beams with GFRP reinforcement, i.e., lower stiffness of the section. At higher load levels, the largest deflection exhibited the beam G1-0, with the smallest stiffness of the reinforcement in the midspan. The beams G1-15 and G1-25 practically had the same average values of deflection during the loading, which is expected due to a small difference in the stiffness of GFRP reinforcement in the beam midspan.

For the beams of Series 2, it could be seen that deflections were fairly uniform during loading, regardless of the different values of the axial stiffness of reinforcement in the critical sections. At higher load levels, the largest deflection was exhibited by beam G2-15 $(\mathrm{EA}=14182 \mathrm{kN})$ and the smallest deflection was exhibited by beam G2-25 $(\mathrm{EA}=15390 \mathrm{kN})$. Nonetheless, the beam G2-0 had significantly lower stiffness in the midspan $(\mathrm{EA}=10734 \mathrm{kN})$, compared to beam G2-15, and also had a lower deflection. This is a consequence of a significant "opposite" moment redistribution from the midspan to the middle support 


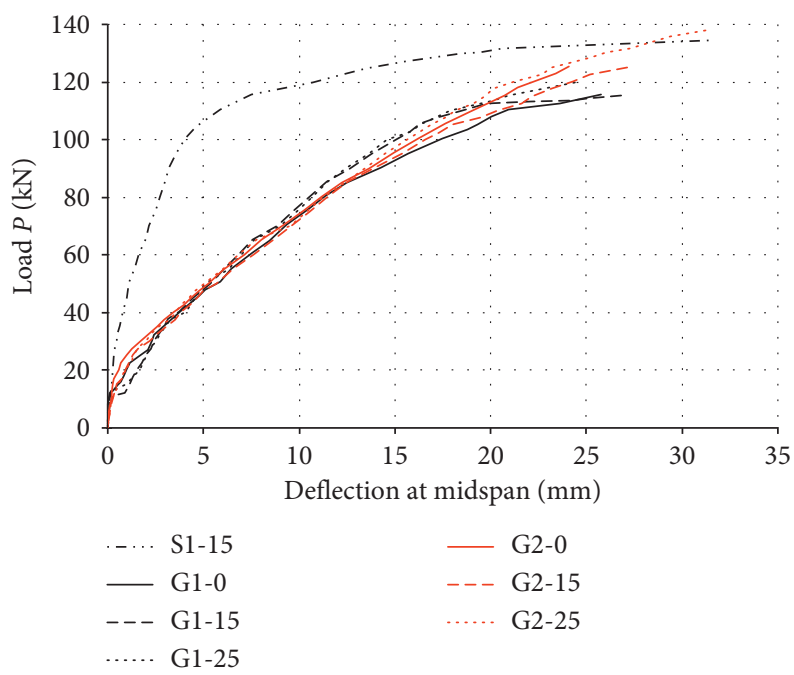

FIGURE 8: Load-deflection relationship at the midspan for tested beams.

(Section 4.5), i.e., significantly lower moment in the midspan of the beam G2-0. It can therefore be concluded that the axial stiffness of the reinforcement in the midspan is of crucial importance not only for the deflection of the beam but also for the axial stiffness ratio of the tensile reinforcement at the middle support and in the midspan.

4.5. Moment Redistribution. Measuring of reactions served for determining internal forces, i.e., bending moments, along the continuous beam, based on which the process of moment redistribution was analyzed. Moment redistribution was obtained by comparing actual bending moments and those obtained by elastic analysis. In Table 4, bending moments at failure and bending moments obtained by elastic analysis are given, similar to the percentage of achieved moment redistribution at failure for all beams.

Development of bending moments and moment redistribution at the middle support for all beams depending on the applied load are given in Figures 9 and 10, respectively. Upturns, i.e., changes in trends, are evident in diagrams of moments and moment redistribution at lower load levels, especially for the beams of Series 1 at appearance of first cracks in the midspan and at the middle support. This could be explained by a sudden change in stiffness of critical sections-from uncracked into cracked section (significant width and height of the cracks). After stabilization of the crack pattern, at higher levels of loads, upturns in diagrams of moment redistribution are less expressed.

Within the beam G1-0, that was designed based on elastic analysis, "opposite" moment redistribution is noticed with a highest value of $23 \%$ after appearance of first cracks. At failure, this value is significantly decreased, and it was $0.5 \%$, which totally corresponded to designed values. "Opposite" redistribution caused the ratio between axial stiffness of tensile GFRP reinforcement between the middle support and midspan that was numbered 1.5. The beam G115 was designed to achieve redistribution of $15 \%$, and it had the relation of axial stiffness of tensile reinforcement in the midspan and at the middle support of 1.38. At failure, moment redistribution at the middle support was significantly increased, and it was numbered $27 \%$. Within the beam G1-25, designed to achieve moment redistribution of $25 \%$, a failure moment redistribution of $18.5 \%$ was achieved, even though the relation between axial stiffness of reinforcement in critical sections was numbered 1.69. For the most levels during loading, the beam G1-25 had moment redistribution higher than 20\% (Figure 10).

Within the beam S1-15 with steel reinforcement, moment redistribution was expected after yielding of reinforcement at the support. Nevertheless, in the diagram of Figure 9, it could be seen that after appearance of cracks, growth of moment at the support was higher than the growth of moment in the midspan. The reason for this fact is that, after yielding of reinforcement at the support, yielding of reinforcement in the midspan also appeared. Then, much higher strains at the middle support than those in the midspan probably lead to the strengthening of reinforcement at the support, which provided acceptance of additional moment. Because of that, moment redistribution was achieved by only $3 \%$. In the diagram of Figure 10, it could be noticed that moment redistribution in the beam S115 was almost always lower than that in the beam G1-15. The reason for this behaviour of the beam S1-15, compared to the beam G1-15, was the relation between stiffness of critical sections. Moreover, a much lower modulus of elasticity of GFRP reinforcement compared to steel provides much wider cracks in beams with GFRP reinforcement, similar to a more dominant influence of reinforcement on the stiffness of section along the continuous beam. Therefore, the ratio between stiffness of critical sections mainly depends on axial stiffness of reinforcement, which provides the large ratio between stiffness of critical sections. In this way, easily could be seen the emphasis of elastic redistribution of internal forces in the beams with GFRP reinforcement in relation to the beams with steel reinforcement.

Within the beam G2-0, designed based on the internal forces obtained by the elastic analysis, at initial load levels, 
TABLe 4: Moments at failure, moments based on elastic analysis, and achieved percentage of moment redistribution.

\begin{tabular}{lcccccc}
\hline Beam & \multicolumn{3}{c}{ Moments at failure (kNm) } & \multicolumn{2}{c}{$\begin{array}{c}\text { Moments based on elastic } \\
\text { analysis (kNm) }\end{array}$} & $\begin{array}{c}\text { Achieved percentage of moment } \\
\text { redistribution at failure (\%) }\end{array}$ \\
& Middle support & Left midspan & Right midspan & Middle support & Midspan & 3.1 \\
\hline S1-15 & 45.1 & 39.2 & 39.9 & 46.6 & 38.8 & -0.5 \\
G1-0 & 40.3 & 32.7 & 33.9 & 40.1 & 33.4 & 26.9 \\
G1-15 & 29.2 & 38.8 & 38.5 & 40.0 & 33.3 & 18.5 \\
G1-25 & 33.8 & 38.2 & 38.7 & 41.5 & 34.6 & -16.4 \\
G2-0 & 50.6 & 31.2 & 34.0 & 43.4 & 36.2 & 18.5 \\
G2-15 & 35.3 & 41.9 & 38.3 & 43.3 & 36.1 & 26.7 \\
G2-25 & 35.0 & 46.8 & 45.7 & 47.8 & 39.8 & \\
\hline
\end{tabular}

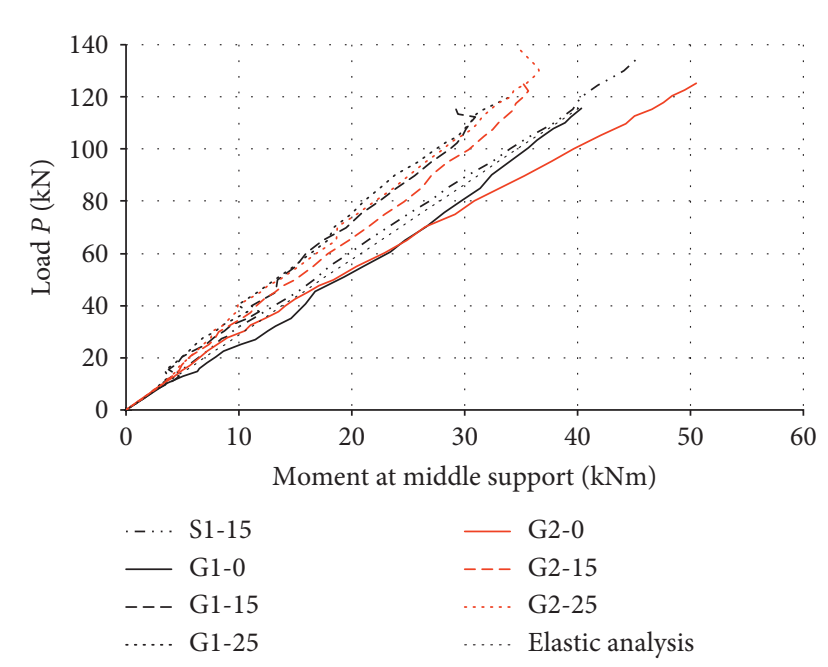

FIGURE 9: Load-moment relationship at the middle support for tested beams.

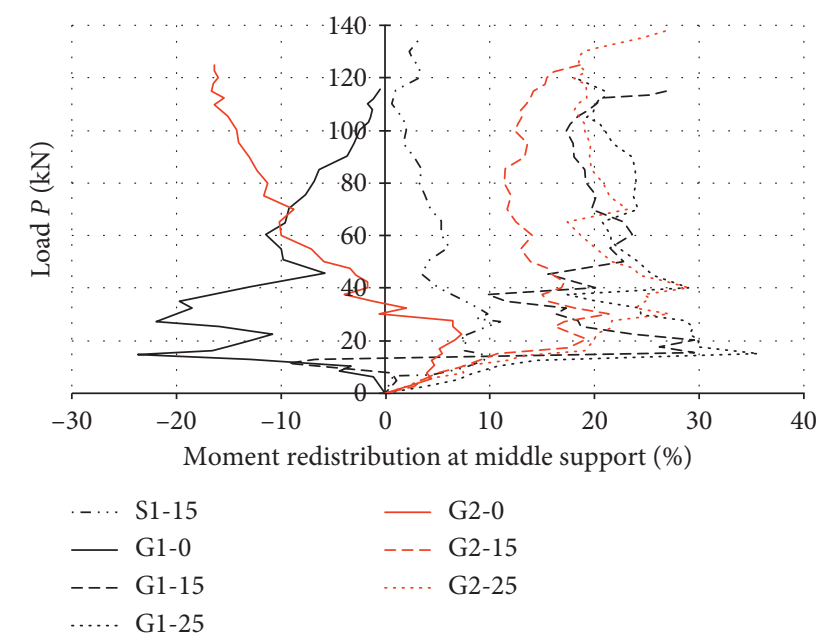

FIGURE 10: Load-percentage of moment redistribution relationship at the middle support for tested beams.

the increase of moment in the midspan was noticed, in relation to the moment at the middle support. After the appearance of the first cracks along the beam, a trend of moment redistribution was changed, i.e., a significant increase of the hogging moment in relation to the moment obtained by the elastic analysis. This trend of moment growth was kept to the failure of the beam. Therefore, "opposite" moment redistribution happened at failure of $16.4 \%$, which was greatly influenced by the axial stiffness ratio of reinforcement at the middle support and in the midspan, which was numbered 1.65. Beams G2-15 and G225 , designed to achieve moment redistribution, from the middle support into the midspan of $15 \%$ and $25 \%$, achieved higher percentage of redistribution at failure of $18.5 \%$ and $26.7 \%$, with ratio of axial stiffness of GFRP reinforcement between critical sections of 1.14 and 1.98 , respectively. During the complete process of loading, beams had positive moment redistribution, which was the result of "set up" of the beams by means of adopted reinforcement, i.e., axial stiffness of reinforcement, which in the cracked section had a great contribution in the stiffness of critical sections, as previously discussed. Within the beams G2-15 and G2-25, an increase in the moment redistribution at failure was observed, probably as a result of the development of full nonlinearity of the compressed concrete.

4.6. The Strains in Reinforcement and Concrete. In Figures 11 and 12, developments of the strains in tensile reinforcement and compressed concrete in the midspan and at the middle support against the applied load for tested beams are given, respectively. It is an evident characteristic upturn in values of the strains in tensile reinforcement after appearance of first cracks in every critical section, which is especially noticed in beams of Series 1 .

For the beams of Series 1, at load levels after appearance of first cracks, the strains in reinforcement in the midspan and at the support were higher in beams with GFRP reinforcement than in beam S1-15 with steel reinforcement. However, at higher load levels, after yielding of steel reinforcement, strain in the beam S1-15 significantly increased and overcame values of strains in beams with GFRP reinforcement. Comparing strains in reinforcement of the beams with strains in GFRP reinforcement, it is evident that, in the midspan, strains were highest in the beam G1-0 as a result of lowest stiffness of this reinforcement, while at the support, strains were highest in the beam G1-25, especially at higher load levels.

Within the beams of Series 2, quite uniform development of strains in the tensile reinforcement in the midspan, regardless of the significant differences in amount, i.e., the axial stiffness of adopted reinforcement of beams, could be noticed. At higher load levels, before failure, strains in the 


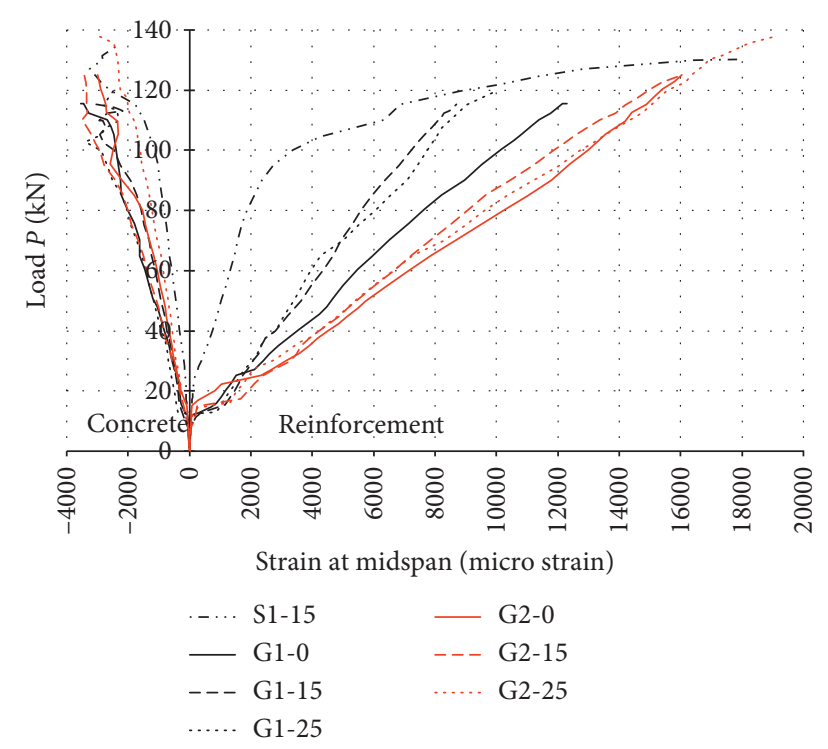

FIGURE 11: Load-strain relationship at the midspan for tested beams.

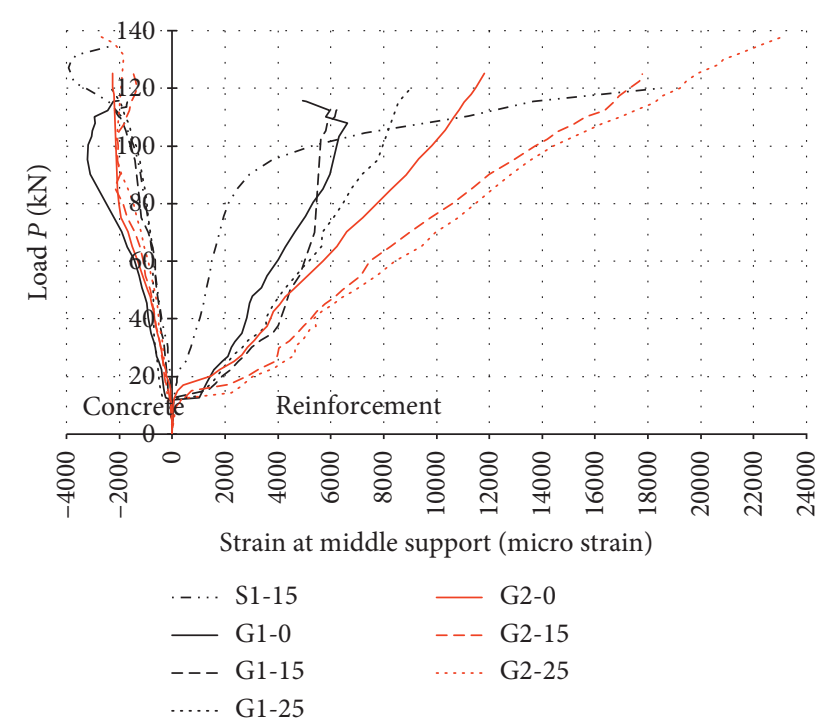

FIGURE 12: Load-strain relationship at the middle support for tested beams.

midspan of the beam G2-0 were about 10\% higher than those in the beam G2-15 and in an average 5\% higher compared to the beam G2-25. At the failure, strains in the beams G20 and G2-15 were practically identical, while the largest strains were in the beam G2-25, which reached the highest load-carrying capacity. As it has been already mentioned, this could be explained by achieved moment redistribution, which contributed that stiffness of reinforcement corresponded to higher bending moments. Because of that, lower strains did not correspond to higher amount of reinforcement, and vice versa. Comparing the strains in the tensile reinforcement at the middle support, the difference in strain values was significantly more pronounced than at the midspan. The higher strains were within the beam G2-25, and the smallest strains were within the beam G2-0, which fully corresponded to the adopted reinforcement at the middle support. The maximum tensile strains did not reach neither the ultimate values nor a single beam of Series 1 and Series 2, which responded to the fact that beams were designed to experience concrete compression failure. The largest measured strains at the middle support were in the beam G2-25 and amounted to $23 \%$, which was very close to the ultimate value of $23.3 \%$ shown in Table 2 .

From Figures 11 and 12, it is noticed that in certain critical sections at the midspan, strain values in the compressed concrete of $3 \%$, which are defined as ultimate by ACI 440.1R-15 [23], have been reached and exceeded, both in the beams of Series 1 and in the beams of Series 2. For some beams, at the middle support, it is also noticed that slightly lower strain values were measured in compressed concrete because at higher load levels, higher than $70 \%$ of failure loads, strains start to decrease, which can be explained by appearance of diagonal cracks near the location of strain gauge.

\section{Comparison of Experimental Results with Code-Predicted Results}

5.1. Load Capacity. All beams were designed in accordance with the ACI 440.1R-15 [23], while CSA S806-12 [24] and EC2-04 [26] were used as control. In designing, data from the manufacturer for GFRP reinforcement were used, so as designed concrete compression strength. Regarding the difference in actual and designed characteristics of materials, different experimental values of failure load were obtained. Calculated failure load was obtained as load at which one of the critical sections reached flexural capacity, i.e., as the lower value of load capacity in the midspan and at the middle support. In determining the calculated failure load, designed moment redistribution from the middle support into the midspan was taken into consideration. In Table 5, experimental failure loads are given in comparison to calculated failure loads, in accordance with the current codes for elements with FRP reinforcement ACI 440.1R-15 [23], CSA S806-12 [24], and EC2-04 [26] for all experimental models.

From Table 5, it is clear that ACI 440.1R-15 [23] provides a very good prediction of failure load for continuous beams with GFRP reinforcement. CSA S806-12 [24] and EC2-04 [26] predict higher values of failure loads than those obtained by experimental tests. This happens because the ACI $440.1 \mathrm{R}-15$ [23] suggests an ultimate strain of $3.0 \%$, and the CSA S806-12 [24] and EC2-04 [26] suggest an ultimate strain of $3.5 \%$. Measured values of strains in concrete, near failure, are closer to values of $3 \%$, which is the reason that obtained experimental failure loads are in agreement with calculated values in accordance with ACI 440.1R-15 [23]. Every beam, in accordance with ACI 440.1R-15 [23], reached calculated load capacity, where for beams of Series 1 relation $P_{\text {exp }} / P_{\text {cal }}$ is $1.0-1.03$ and for beams of Series 2 it is $1.07-1.24$.

Although the beams of Series 1 and Series 2 with GFRP reinforcement were designed to achieve similar failure loads, some higher values of failure loads were obtained for beams 
TABLE 5: Experimental and calculated failure loads for tested beams.

\begin{tabular}{|c|c|c|c|c|c|c|c|}
\hline \multirow{2}{*}{ Beam } & \multicolumn{4}{|c|}{ Failure load-load-carrying capacity (kN) } & \multicolumn{3}{|c|}{$P_{\text {exp }} / P_{\text {cal }}$} \\
\hline & Experiment & ACI & CSA & $\mathrm{EC} 2$ & Exp./ACI & Exp./CSA & Exp./EC2 \\
\hline S1-15 & 134.3 & 90.1 & 88.8 & 90.1 & 1.49 & 1.51 & 1.49 \\
\hline G1-0 & 115.6 & 115.4 & 126.3 & 141.3 & 1.00 & 0.92 & 0.82 \\
\hline G1-15 & 115.2 & 111.8 & 123.0 & 137.0 & 1.03 & 0.94 & 0.84 \\
\hline G1-25 & 119.6 & 117.4 & 128.6 & 143.8 & 1.02 & 0.93 & 0.83 \\
\hline G2-0 & 125.2 & 113.6 & 128.0 & 145.2 & 1.10 & 0.98 & 0.86 \\
\hline G2-15 & 124.9 & 117.2 & 131.7 & 149.8 & 1.07 & 0.95 & 0.83 \\
\hline G2-25 & 137.8 & 110.8 & 125.2 & 141.7 & 1.24 & 1.10 & 0.97 \\
\hline
\end{tabular}

of Series 2. The reason for this phenomenon could be the sliding of GFRP reinforcement and surrounding concrete in the beams of Series 1. Reducing the amount of GFRP reinforcement at the middle support and increase in the midspan of continuous beams, as a result of designed moment redistribution, did not have influence on decrease of load capacity of continuous beams. Moreover, the beams G1-25 and G2-25, with the designed moment redistribution of $25 \%$, achieved higher load capacity, compared to the beams with a designed moment redistribution of $0 \%$ and $15 \%$, for $5 \%$ and $10 \%$, respectively.

5.2. Load-Deflection Response. In the background of this paper, it is stated that, until now, as a result of a number of research studies on investigation of behavior of simple beams with FRP reinforcement, a number of expressions for determining deflection-load response is suggested. For calculation of deflection of continuous beams, loaded by concentrated forces at the middle of the span, the following equation obtained by elastic analysis is used:

$$
\Delta=\frac{7}{768} \cdot \frac{P L^{3}}{E_{\mathrm{c}} I_{\mathrm{e}}},
$$

where stiffness $E_{\mathrm{c}} I_{\mathrm{e}}$ is used and $I_{\mathrm{e}}$ represents the effective moment of inertia of the considered section. Effective moment of inertia $I_{\mathrm{e}}$ is calculated at both critical sections as follows:

$$
I_{\mathrm{e}}=0.85 I_{\mathrm{em}}+0.15 I_{\mathrm{ec}}
$$

where $I_{\mathrm{em}}$ and $I_{\mathrm{ec}}$ are the effective moment of inertia at the midspan and at the middle support, respectively.

ACI 440.1R-15 [23] suggests an equation for determining effective moment of inertia based on research studies made by Bischoff and Gross [9] with a remark that it could also be used, with a great degree of reliability, for elements with steel reinforcement and for elements with FRP reinforcement, without empirical parameters:

$$
I_{\mathrm{e}}=\frac{I_{\mathrm{cr}}}{1-\gamma \cdot\left(M_{\mathrm{cr}} / M_{\mathrm{a}}\right)^{2} \cdot\left(1-I_{\mathrm{cr}} / I_{\mathrm{g}}\right)},
$$

where $\gamma$ is the integration factor that influences stiffness variation along elements, and for the beams loaded by concentrated forces, it is calculated from the following expression:

$$
\gamma=3-2 \cdot\left(\frac{M_{\mathrm{cr}}}{M_{\mathrm{a}}}\right) .
$$

Calculation of deflection, in accordance with CSA S80612 [24], is based on relation to the moment-curvature along the span. For calculation of deflection of continuous beams on two spans loaded by concentrated forces in the middle of the spans, the following expression can be used:

$$
\Delta_{\max }=\frac{P L^{3}}{48 E_{\mathrm{c}} I_{\mathrm{cr}}}\left(\frac{5}{16}-\frac{15}{8}\left(1-\frac{I_{\mathrm{cr}}}{I_{\mathrm{g}}}\right) \cdot\left(\frac{L_{\mathrm{g}}}{L}\right)^{3}\right) .
$$

Habeeb and Ashour [15] investigated behavior of continuous beams with GFRP reinforcement, and they suggested modification of expression for calculation of deflection of continuous beams, i.e., effective moment of inertia that is given in ACI 440.1R-06 [28]:

$$
I_{\mathrm{e}}=\left(\frac{M_{\mathrm{cr}}}{M_{\mathrm{a}}}\right)^{3} \cdot \beta_{\mathrm{d}} \cdot I_{\mathrm{g}}+\left(1-\left(\frac{M_{\mathrm{cr}}}{M_{\mathrm{a}}}\right)^{3}\right) \cdot I_{\mathrm{cr}} \cdot \gamma_{\mathrm{G}} \leq I_{\mathrm{g}},
$$

where the factor $\beta_{\mathrm{d}}$ reduces tension stiffening for elements with FRP reinforcement, and it is given as follows:

$$
\beta_{\mathrm{d}}=\frac{1}{5} \frac{\rho_{\mathrm{f}}}{\rho_{\mathrm{fb}}} \leq 1.0,
$$

and where $\gamma_{\mathrm{G}}=0.6$ is a reduction factor, and it is introduced into calculation for the condition after the appearance of cracks because it is concluded that modified Branson's equation underestimates deflections for higher load levels.

Kara and Ashour [19] concluded, based on previous research studies on continuous beams with FRP reinforcement $[1,15,16]$, that current codes underestimate deflections of continuous beams due to appearance of wide cracks above the middle support, that influence a significant decrease of effective stiffness of the section. Modified stiffness of the section in the midspan of continuous beams through effective moment of inertia is suggested:

$$
I_{\mathrm{e}}=I_{\mathrm{cr}} \cdot \frac{\alpha}{1-0.5 \cdot(1-\alpha) \cdot\left(M_{\mathrm{cr}} / M_{\mathrm{ser}}\right)},
$$

where $\alpha$ is the reduction factor for beams with GFRP and AFRP reinforcement given by the following expression:

$$
\alpha=0.65 \cdot\left(0.7+0.36 \cdot \frac{E_{\mathrm{f}}}{E_{\mathrm{s}}} \cdot \frac{\rho_{\mathrm{f}}}{\rho_{\mathrm{fb}}}\right) \leq 0.65 .
$$


Ju et al. [11] proposed a semiempirical model for determining the effective moment of inertia, which is based on the modification of the Branson's equation, following the approach of Toutanji and Saffi [7]. A nonlinear parameter $K$ is introduced which reduces the effective moment of inertia at higher load levels. The equations are proposed as follows:

$$
\begin{aligned}
I_{e} & =\left(\frac{M_{\mathrm{cr}}}{M_{\mathrm{a}}}\right)^{m} \cdot I_{\mathrm{g}}+\left(1-\left(\frac{M_{\mathrm{cr}}}{M_{\mathrm{a}}}\right)^{m}-K\right) \cdot I_{\mathrm{cr}} \leq I_{\mathrm{g}}, \\
m & =6-13 \cdot \rho_{\mathrm{f}} \frac{E_{\mathrm{f}}}{E_{\mathrm{s}}} \\
K & =\left(\frac{1}{11} \cdot\left(\frac{M_{\mathrm{cr}}}{M_{\mathrm{a}}}\right)\right)^{4} .
\end{aligned}
$$

Load-deflection diagrams obtained by calculation according to expression (1), using effective moment of inertia according to ACI 440.1R-15 [23], CSA S806-12 [24], Ju et al. [11], Habeeb and Ashour [15], and Kara and Ashour [19], are compared to experimental results in Figure 13 for all beams. Since the cracking moment $M_{\mathrm{cr}}$ is key to the accuracy of the deflection calculation, the experimental values were used for all models in order to eliminate its influence on the characteristics of the curve. In accordance with ACI 440.1R-15 [23], CSA S806-12 [24], and Ju et al. [11], for the beams of Series 1, already at initial load levels, deflections obtained by the experiment are higher than calculated deflections, and for the beams of Series 2, there is a matching for experimental and calculated diagrams only for the loads that correspond to $35-40 \%$ of the failure load. For higher load levels, the values obtained by the experiment are higher than calculated. The suggested model for deflection calculation according to Habeeb and Ashour [15] shows better agreement with experimental results. At loads near failure, exceptions occur, primarily due to additional fall of the deflection-load curve obtained by the experiment, when it comes to full development of nonlinearity of concrete. Kara and Ashour's model for deflection calculation [19] for continuous beams with GFRP reinforcement overestimates deflections especially for lower load levels for all beams.

In order to overcome stated shortcomings of the previous models, a modified model for calculation of deflection is proposed. The model is based on Branson's equation used in ACI 440.1R-06 [28] introducing a coefficient with a value of 0.7 , which reduces the effective moment of inertia after the appearance of cracks, in analogy with Habeeb and Ashour's model [15], and a nonlinear parameter $K$, proposed by Ju et al. [11], which additionally reduces the effective moment of inertia at higher load levels:

$$
I_{\mathrm{e}}=\left(\frac{M_{\mathrm{cr}}}{M_{\mathrm{a}}}\right)^{3} \cdot \beta_{\mathrm{d}} \cdot I_{\mathrm{g}}+\left(1-\left(\frac{M_{\mathrm{cr}}}{M_{\mathrm{a}}}\right)^{3}-K\right) \cdot I_{\mathrm{cr}} \cdot 0.7 \leq I_{\mathrm{g}}
$$

The very good match of the proposed model and experimental results was shown, both at lower and at higher load levels. The exception occurs in the beams G1-15 and G1-25 at loads immediately after cracking where a large increase in deflection happened, which indicates poor bond strength between GFRP bars and concrete in these beams. In particular, it is noted that the proposed model, using the coefficient $K$ defined by Ju et al. [11], describes good development of deflection for higher load levels close to failure, when it comes to full development of nonlinearity of concrete and an additional drop in the slope of the deflectionload curve. Further experimental testing would be required to verify the proposed model.

\section{Conclusions}

The subject of the experimental research shown in this paper is consideration of six continuous beams reinforced with GFRP reinforcement loaded by concentrated forces in the middle of the span, until failure, for different arrangements of reinforcement along the beam. Results of experimental research studies are compared to provisions of current regulations and codes by means of load capacity and load-deflection response. Based on these research results, following conclusions could be made:

(i) Continuous beams with GFRP reinforcement have the ability of moment redistribution in relation to moments obtained by linear elastic analysis, after appearance of first cracks in concrete. Values of moment redistribution dominantly depend on stiffness of critical sections at the support and in the midspan, which, primarily, due to wide and deep cracks, come to relation of axial stiffness of GFRP reinforcement in critical sections. Elastic redistribution of internal forces is based on this.

(ii) Continuous beams with GFRP reinforcement show significant warnings before failure, in terms of large deflections and wide and deep cracks. It is specially defined additional curving of the deflection diagram at loads close to failure, as a result of the development of full nonlinearity of the compressed concrete.

(iii) Reducing the amount of GFRP reinforcement at the middle support and increase of amount of GFRP reinforcement in the midspan of continuous beams, as a result of designed moment redistribution, in relation to the moments obtained by elastic analysis, do not have negative influence on load capacity of continuous beams and mainly influence the decrease of deflection. By increasing the designed moment redistribution to $25 \%$, the load-carrying capacity increases by $5 \%$ to $10 \%$ in the beams with GFRP reinforcement.

(iv) Wide and deep cracks that are formed in critical sections of continuous beams with wrapped GFRP bars with the unsaturated polyester matrix, in a smaller number compared to beams reinforced by steel reinforcement or GFRP bars with rebars and epoxy matrix, point out at poor bond strength 

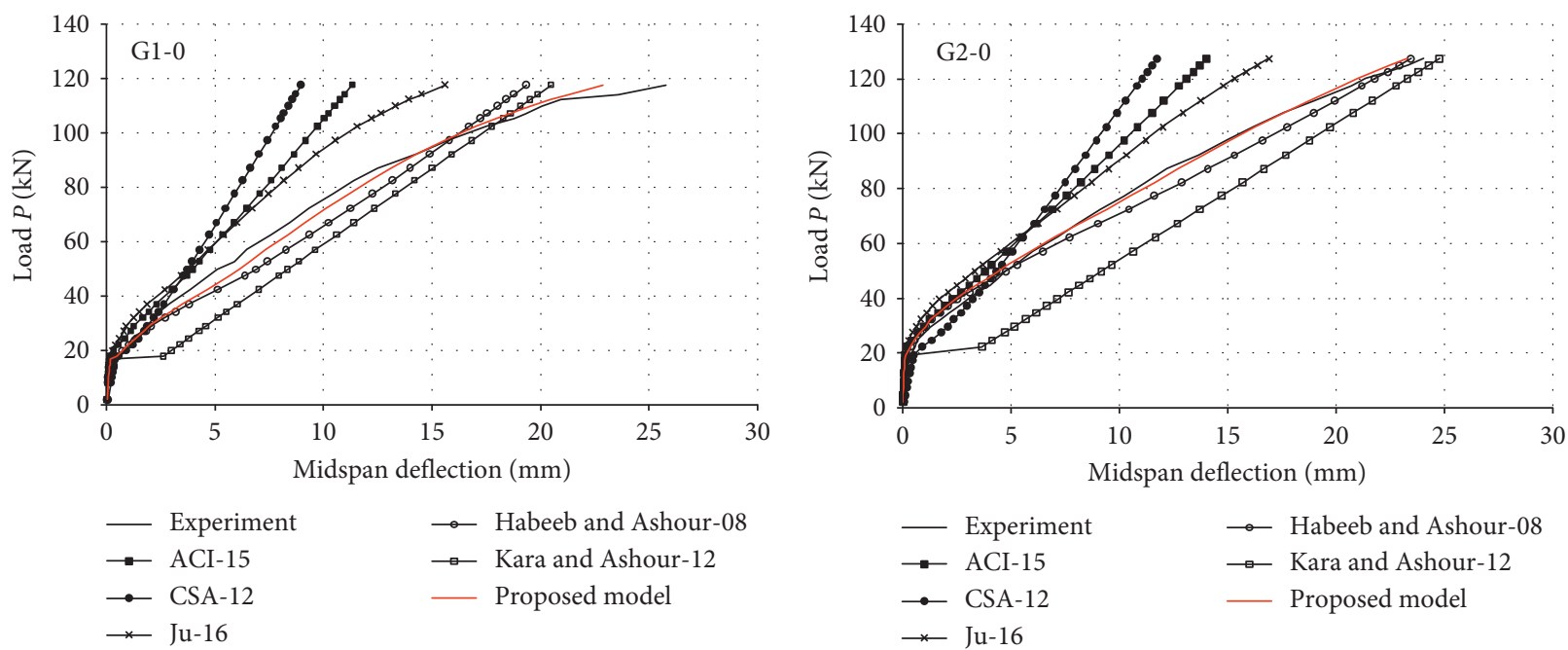

(a)

(b)
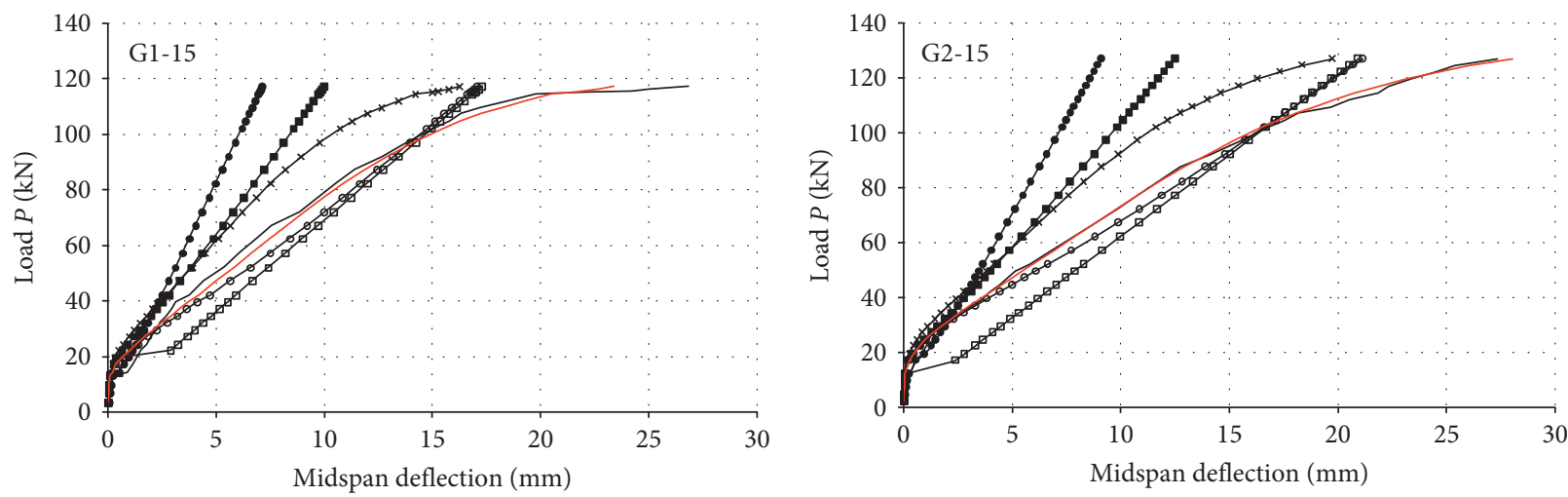
- Experiment
$\therefore$ Habeeb and Ashour-08
$\rightarrow$ ACI-15
$\rightarrow$ Kara and Ashour-12
$\rightarrow$ CSA-12
_ Proposed model
$\rightarrow$ Ju-16

(c)

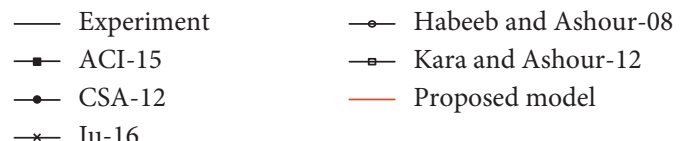

$\rightarrow$ Ju-16

(d)
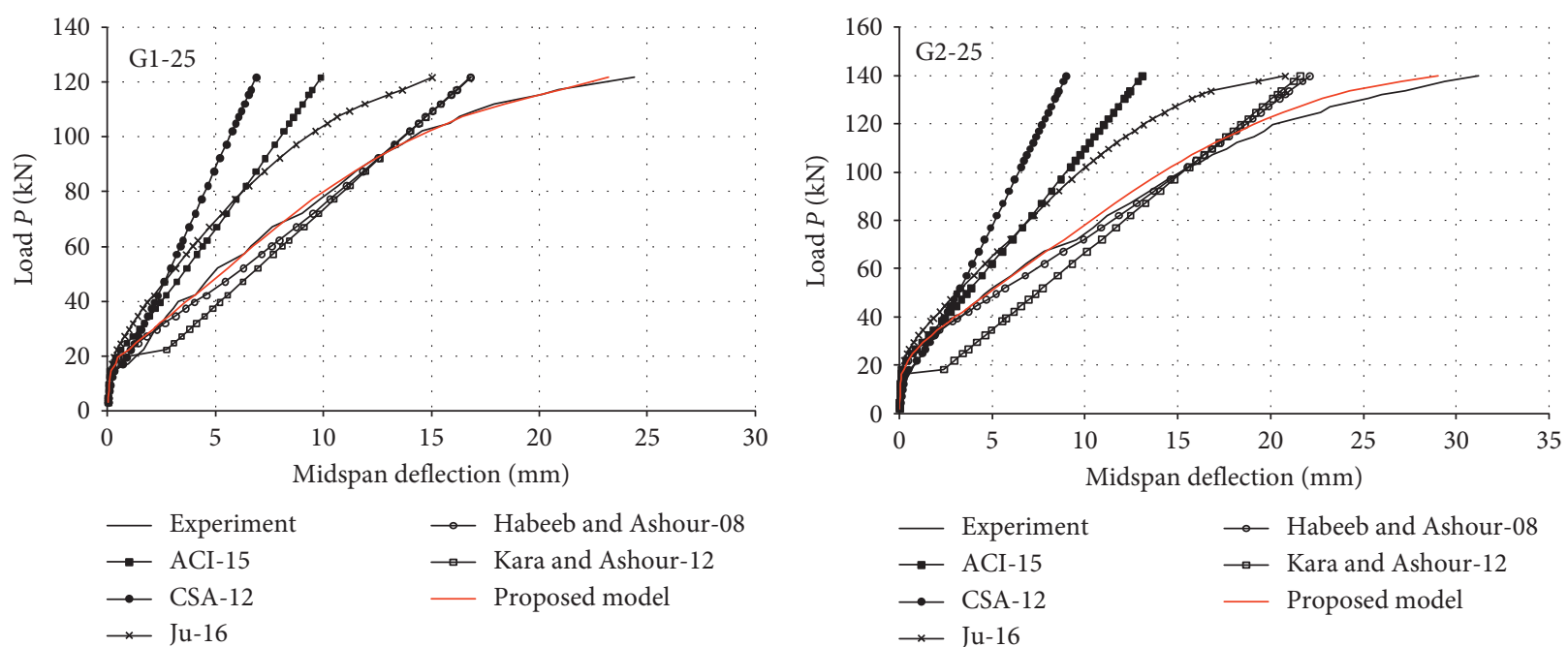

(e)

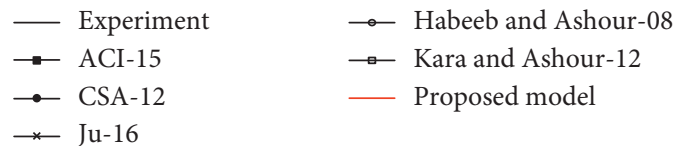

(f)

Figure 13: Experimental and predicted deflection for tested beams. (a) G1-0. (b) G2-0. (c) G1-15. (d) G2-15. (e) G1-25. (f) G2-25. 
between GFRP reinforcement and surrounding concrete. On the contrary, beams with GFRP reinforcement with rebars and epoxy matrix, based on development of the cracks of the beams, indicate very good bond strength between GFRP reinforcement and concrete.

(v) ACI 440.1R-15 [23] reasonably predicts failure load for continuous beams with GFRP reinforcement, for overreinforced sections. CSA S806-12 [24] and EC2-04 [26] predict quite higher values of failure loads than those obtained by the experiment.

(vi) Current codes ACI 440.1R-15 [23] and CSA S80612 [24] underestimate deflection of continuous beams with GFRP reinforcement for higher load levels. Habeeb and Ashour's suggested model [15] shows better agreement to experimental results. The proposed model for calculation of deflection of continuous beams with GFRP reinforcement shows very good prediction to experimental results, during the entire loading process.

\section{Nomenclature}

$P: \quad$ Applied load at the midpoint of each span $(\mathrm{kN})$

$P_{\mathrm{u}}$ : Load at failure $(\mathrm{kN})$

$P_{\text {cr }}:$ Load at the first crack $(\mathrm{kN})$

$P_{\text {exp }}$ : Experimental failure load $(\mathrm{kN})$

$P_{\text {cal }}$ : Calculated failure load $(\mathrm{kN})$

$L: \quad$ Beam span $(\mathrm{mm})$

$L_{\mathrm{g}}$ : Uncracked length at half of the beam ( $\left.\mathrm{mm}\right)$

$I_{\mathrm{g}}$ : Moment of inertia of the gross section $\left(\mathrm{mm}^{4}\right)$

$I_{\mathrm{cr}}$ : Cracked moment of inertia $\left(\mathrm{mm}^{4}\right)$

$I_{\mathrm{e}}$ : Effective moment of inertia $\left(\mathrm{mm}^{4}\right)$

$M_{\mathrm{cr}}$ : Cracking moment $(\mathrm{kNm})$

$M_{\mathrm{a}}$ : Applied moment $(\mathrm{kNm})$

$A_{\mathrm{f}}$ : Cross-sectional area of tensile GFRP reinforcement $\left(\mathrm{mm}^{2}\right)$

$E_{\mathrm{f}}: \quad$ Modulus of elasticity of GFRP reinforcement $(\mathrm{MPa})$

$E_{s}: \quad$ Modulus of elasticity of steel reinforcement (MPa)

$E_{\mathrm{c}}$ : Modulus of elasticity of concrete $(\mathrm{MPa})$

$f_{\mathrm{f}}$ : Tensile strength of GFRP reinforcement $(\mathrm{MPa})$

$f_{\mathrm{y}}$ : Yield strength of steel reinforcement $(\mathrm{MPa})$

$f_{\mathrm{c}}$ : Concrete compressive strength of cylinder ( $\left.\mathrm{MPa}\right)$

$\varepsilon_{\mathrm{fu}}$ : Ultimate strain of GFRP reinforcement

$\varepsilon_{\mathrm{y}}$ : Yield strain of steel reinforcement

$\varepsilon_{\mathrm{cu}}$ : Ultimate strain of concrete

$\rho_{\mathrm{f}}: \quad$ GFRP reinforcement ratio

$\rho_{\mathrm{fb}}:$ Balanced GFRP reinforcement ratio

$\gamma_{\mathrm{G}}$ : Proposed reduction factor used in the calculation of the effective moment of inertia for the continuous beam with GFRP reinforcement

$\alpha$ : Proposed reduction factor used in the calculation of the effective moment of inertia for the continuous beam with FRP reinforcement

$\beta_{\mathrm{d}}$ : Reduction factor used in the calculation of the effective moment of inertia

$\Delta: \quad$ Deflection at the midspan of the beam $(\mathrm{mm})$.

\section{Data Availability}

The data used to support the findings of this study are available from the corresponding author upon request.

\section{Conflicts of Interest}

The authors declare that there are no conflicts of interest regarding the publication of this paper.

\section{Acknowledgments}

The authors would like to express their gratitude to the Engineering Chamber of Montenegro for the financial support and China Road and Bridge Corporation Montenegro Branch for the donation of GFRP reinforcement for this research, and local construction companies from Montenegro for the donation of concrete admixtures. Also, the first author is grateful for the technical help of the Laboratory of the Faculty of Civil Engineering at the University of Montenegro.

\section{References}

[1] M. El-Mogy, A. El-Ragaby, and E. El-Salakawy, "Flexural behavior of continuous FRP-reinforced concrete beams," Journal of Composites Construction, vol. 14, no. 6, pp. 669680, 2010.

[2] R. H. Scott and R. T. Whittle, "Moment redistribution effects in beams," Magazine of Concrete Research, vol. 57, no. 1, pp. 9-20, 2005.

[3] M. El-Mogy, A. El-Ragaby, and E. El-Salakawy, "Effect of transverse reinforcement on the flexural behavior of continuous concrete beams reinforced with FRP," Journal of Composites for Construction, vol. 15, no. 5, pp. 672-681, 2011.

[4] D. Mostofinejad, Ductility and moment redistribution in continuous FRP reinforced concrete beams, Ph.D. thesis, Department of Civil and Environmental Engineering, Carleton University, Ottawa, ON, Canada, 1997.

[5] H. Wang and A. Belarbi, "Ductility characteristics of fiberreinforced-concrete beams reinforced with FRP rebars," Construction and Building Materials, vol. 25, no. 5, pp. 2391-2401, 2011.

[6] M. M. Rafi, A. Nadjai, F. Ali, and D. Talamona, "Aspects of behavior of CFRP reinforced concrete beams in bending," Construction and Building Materials, vol. 22, no. 3, pp. 277285, 2008.

[7] H. A. Toutanji and M. Saafi, "Flexural behaviour of concrete beams reinforced with glass fiber-reinforced polymer GFRP bars," ACI Structural Journal, vol. 97, no. 5, pp. 712-719, 2000.

[8] J. R. Yost, S. P. Gross, and D. W. Dinehart, "Effective moment of inertia for glass fiber-reinforced polymer-reinforced concrete beams," ACI Structural Journal, vol. 100, no. 6, pp. 732-739, 2003.

[9] P. H. Bischoff and S. P. Gross, "Equivalent moment of inertia based on integration of curvature," Journal of Composites for Construction, vol. 15, no. 3, pp. 263-273, 2011.

[10] S. R. Mousavi and M. R. Esfahani, "Effective moment of inertia prediction of FRP-reinforced concrete beams based on experimental results," Journal of Composites Construction, vol. 16, no. 5, pp. 490-498, 2012. 
[11] M. Ju, H. Oh, J. Lim, and J. Sim, "A modified model for deflection calculation of reinforced concrete beam with deformed GFRP rebar," International Journal of Polymer Science, vol. 2016, Article ID 2485825, 10 pages, 2016.

[12] C. Barris, L. Torres, A. Turon, M. Baena, and A. Catalan, "An experimental study of the flexural behaviour of GFRP RC beams and comparison with prediction models," Composite Structures, vol. 91, no. 3, pp. 286-295, 2009.

[13] C. Barris, L. Torres, J. Comas, and C. Mias, "Cracking and deflections in GFRP RC beams: an experimental study," Composites Part B: Engineering, vol. 55, pp. 580-590, 2013.

[14] N. F. Grace, A. K. Soliman, G. Abdel-Sayed, and K. R. Saleh, "Behavior and ductility of simple and continuous FRP reinforced beams," Journal of Composites for Construction, vol. 2, no. 4, pp. 186-194, 1998.

[15] M. N. Habeeb and A. F. Ashour, "Flexural behavior of continuous GFRP reinforced concrete beams," Journal of Composites Construction, vol. 12, no. 2, pp. 115-124, 2008.

[16] A. F. Ashour and M. N. Habeeb, "Continuous concrete beams reinforced with CFRP bars," Proceedings of the Institution of Civil Engineers-Structures and Buildings, vol. 161, no. 6, pp. 349-357, 2008.

[17] B. Matos, J. R. Correia, L. M. S. Castro, and P. França, "Structural response of hyperstatic concrete beams reinforced with GFRP bars: effect of increasing concrete confinement," Composite Structures, vol. 94, no. 3, pp. 1200-1210, 2012.

[18] P. Santos, G. Laranja, P. M. Franca, and J. R. Correia, "Ductility and moment redistribution capacity of multi-span T-section concrete beams reinforced with GFRP bars," Construction and Building Materials, vol. 49, pp. 949-961, 2013.

[19] I. F. Kara and A. F. Ashour, "Flexural performance of FRP reinforced concrete beams," Composite Structures, vol. 94, no. 5, pp. 1616-1625, 2012.

[20] I. F. Kara and A. F. Ashour, "Moment redistribution in continuous FRP reinforced concrete beams," Construstion and Building Materials, vol. 49, pp. 939-948, 2013.

[21] T. Lou, S. M. R. Lopes, and A. V. Lopes, "Neutral axis depth and moment redistribution in FRP and steel reinforced concrete continuous beams," Composites Part B: Engineering, vol. 70, pp. 44-52, 2015.

[22] K. Mahmoud and E. El-Salakawy, "Shear strength of GFRPreinforced concrete continuous beams with minimum transverse reinforcement," Journal of Composites for Construction, vol. 18, no. 1, article 4013018, 2014.

[23] ACI Committee 440, Guide for the Design and Construction of Structural Concrete Reinforced with Fiber-Reinforced Polymer (FRP) Bars (ACI 440.1R-15), American Concrete Institute, Farmington Hills, MI, USA, 2015.

[24] CSA S806-12, Design and Construction of Buildings Components with Fiber-Reinforced Polymers, Canadian Standards Association (CSA), Toronto, ON, Canada, 2012.

[25] CNR-DT 203/2006, Guide for the Design and Construction of Concrete Structures Reinforced with Fiber-Reinforced Polymer Bars, National Research Council, Rome, Italy, 2006.

[26] EN 1992-1-1, Eurocode 2: Design of Concrete Structures: General Rules and Rules for Buildings, Part 1-1, CEN, Brussels, Belgium, 2004.

[27] ACI Committee 440, Guide Test Methods for Fiber-Reinforced Polymers (FRPs) for Reinforcing or Strengthening Concrete Structures (ACI 440.3R-12), American Concrete Institute, Farmington Hills, MI, USA, 2012.

[28] ACI Committee 440, Guide for the Design and Construction of Structural Concrete Reinforced with FRP Bars (ACI 440.1R-06), American Concrete Institute, Farmington Hills, MI, USA, 2006. 


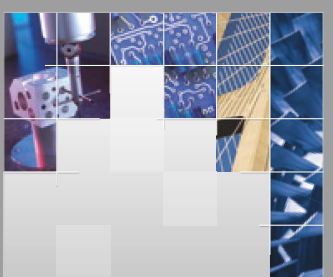

\section{Enfincering}
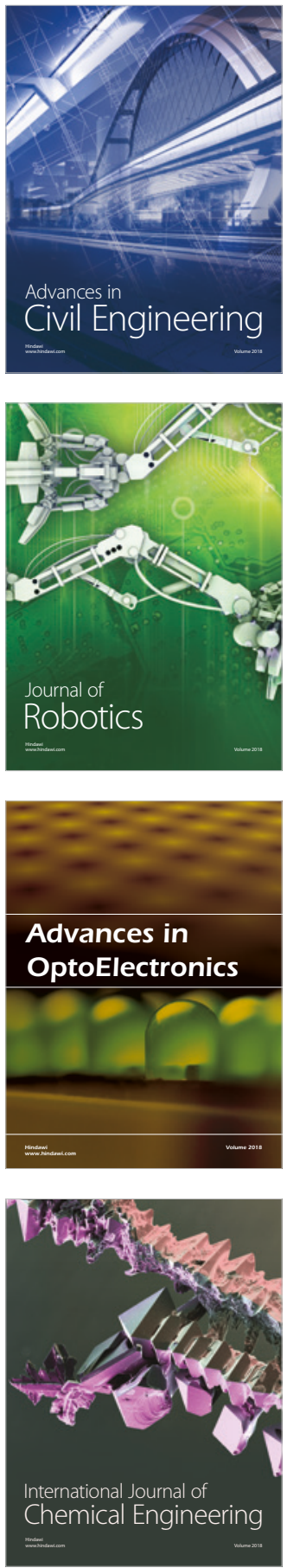

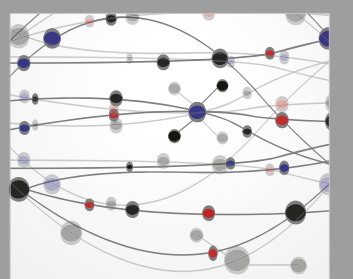

\section{Rotating \\ Machinery}

The Scientific World Journal

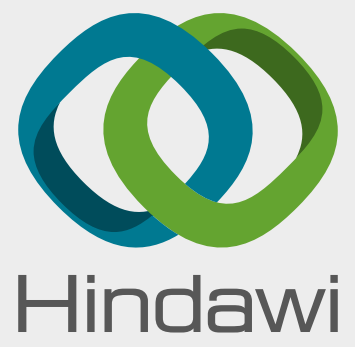

Submit your manuscripts at

www.hindawi.com
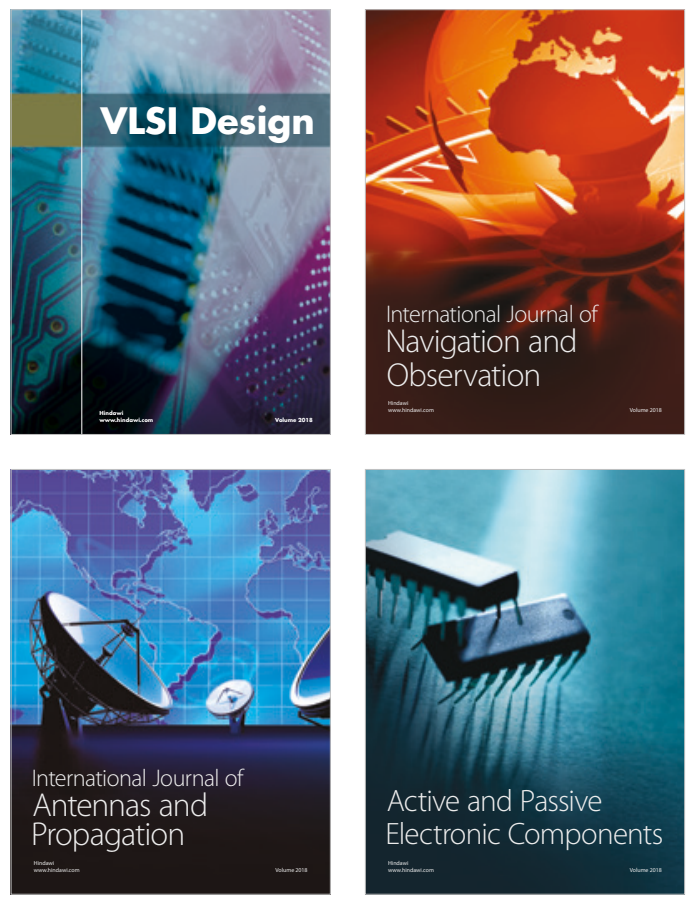
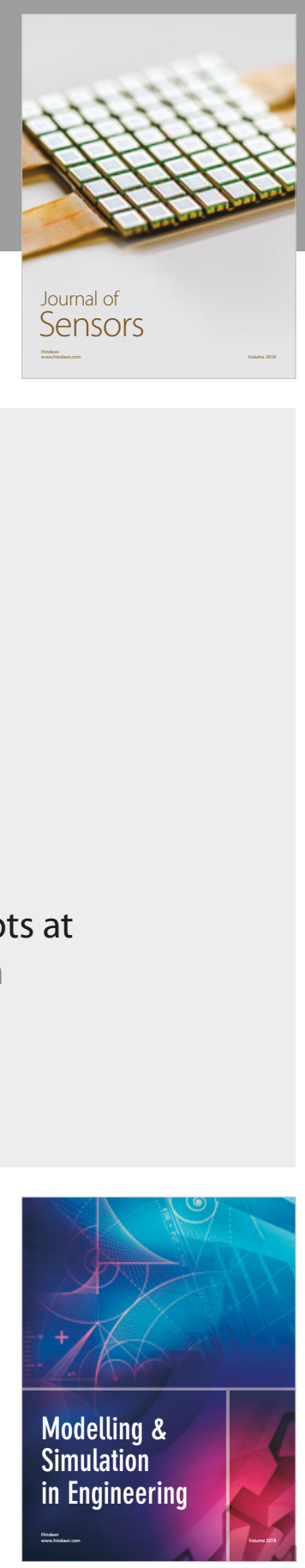

\section{Advances \\ Multimedia}
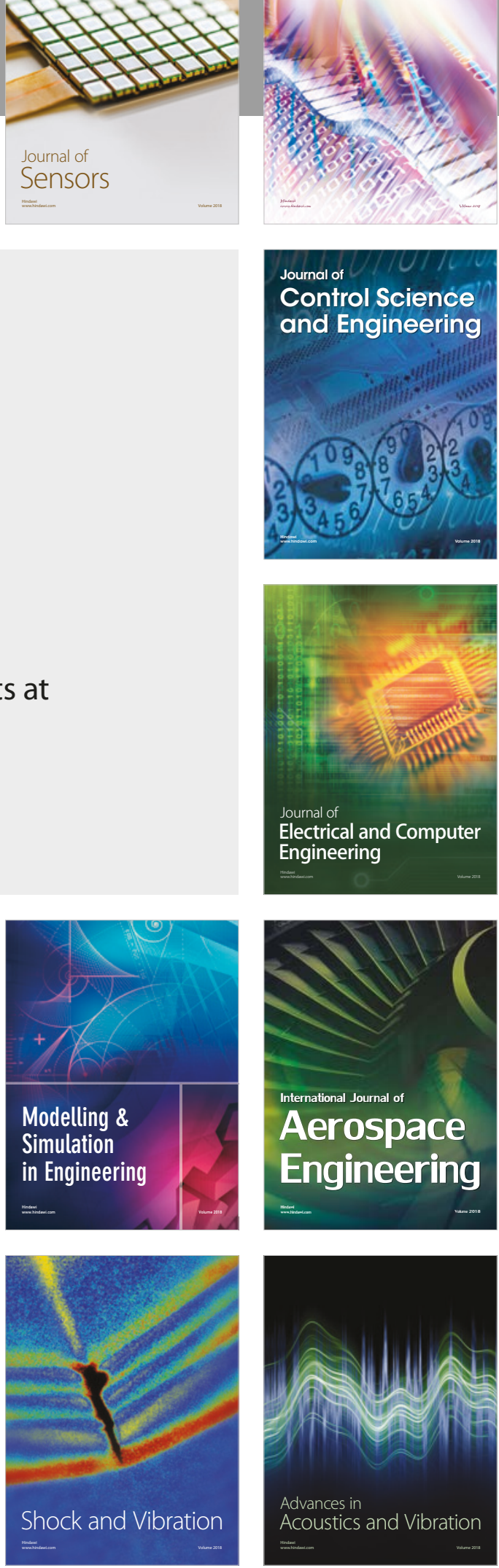